\title{
Recent Advances of Exciplex-Based White Organic Light-Emitting Diodes
}

\author{
Peng Xiao ${ }^{1}$, Junhua Huang ${ }^{1}$, Yicong Yu ${ }^{1, *}$, Jian Yuan ${ }^{1}$, Dongxiang Luo ${ }^{2, *}$, Baiquan Liu ${ }^{3,4, *}$ and \\ Dong Liang ${ }^{4}$ \\ 1 School of Physics and Optoelectronic Engineering, Foshan University, Foshan 528000, China; \\ xiaopeng@fosu.edu.cn (P.X.); jamha1212@163.com (J.H.); yuanjian054@163.com (J.Y.) \\ 2 School of Materials and Energy, Guangdong University of Technology, Guangzhou 510006, China \\ 3 LUMINOUS! Center of Excellent for Semiconductor Lighting and Displays, School of Electrical and \\ Electronic Engineering, Nanyang Technological University, Nanyang Avenue, Singapore 639798, Singapore \\ 4 State Key Laboratory of Luminescent Materials and Devices, Institute of Polymer Optoelectronic Materials \\ and Devices, South China University of Technology, Guangzhou 510640, China; 1d578226@163.com \\ * Correspondence: yicong2007@gmail.com (Y.Y.); luodx@gdut.edu.cn (D.L.); bqliu@ntu.edu.sg (B.L.)
}

Received: 24 July 2018; Accepted: 20 August 2018; Published: 24 August 2018

\begin{abstract}
Recently, exciplexes have been actively investigated in white organic light-emitting diodes (WOLEDs), since they can be effectively functioned as (i) fluorescent or thermally activated delayed fluorescent (TADF) emitters; (ii) the hosts of fluorescent, phosphorescent and TADF dopants. By virtue of the unique advantages of exciplexes, high-performance exciplex-based WOLEDs can be achieved. In this invited review, we have firstly described fundamental concepts of exciplexes and their use in organic light-emitting diodes (OLEDs). Then, we have concluded the primary strategies to develop exciplex-based WOLEDs. Specifically, we have emphasized the representative WOLEDs using exciplex emitters or hosts. In the end, we have given an outlook for the future development of exciplex-based WOLEDs.
\end{abstract}

Keywords: exciplex; white; TADF; electroplex; OLED

\section{Introduction}

Organic light-emitting diodes (OLEDs) have great potential for the new-generation flat-panel displays and solid-state lighting, since they possess many advantages such as high efficiency, broad viewing angle, saving energy, thin thickness as well as flexibility [1-5]. In 1987, the first OLED was invented by Tang et al. in Eastman Kodak Company [6]. For that device, an external quantum efficiency (EQE) of $1 \%$, power efficiency (PE) of $1.5 \mathrm{~lm} \mathrm{~W}^{-1}$ and luminance of $>1000 \mathrm{~cd} \mathrm{~m}^{-2} @<10 \mathrm{~V}$ green fluorescence originating from singlet excitons could be obtained, which demonstrated that organic materials were indeed viable alternatives for optoelectronic applications. Then, Ma and coworkers fabricated the first phosphorescent OLEDs by using osmium(II) complexes in 1998, however, only poor efficiency was obtained [7]. Later, Forrest et al. established highly efficient phosphorescent OLEDs with the Pt-complexes [8]. In their device, phosphors can realize a theoretical unity internal quantum efficiency (IQE), since phosphors can harvest both singlets and triplets due to the heavy-atom effect [9-14]. In 2012, thermally activated delayed fluorescence (TADF) materials have been reported by Adachi and coworkers, where the energy gap $\left(\Delta_{\mathrm{EST}}\right)$ for triplet excited state $\left(\mathrm{T}_{1}\right)$ and singlet excited state $\left(S_{1}\right)$ should be small enough [15]. To date, TADF materials have been considered to be the third-generation emitters of OLEDs, owing to the noble-metal-free characteristic and 100\% exciton harvesting efficiency [16-20].

With the development of emitters, the performance of OLEDs has been step-by-step enhanced and nowadays can satisfy the demand of real commercialization for handphones, lamps and televisions. 
Besides, with the understanding of OLED technology, many concepts of OLEDs have also been applied to develop the related optoelectronic techniques, particularly for other LEDs, such as polymer LEDs [21-24], quantum-dot light-emitting diodes (LEDs) [25-29], nanoplatelet LEDs [30-32] and perovskite LEDs [33-38]. Therefore, how to further enhance the performance of OLEDs is also significant to other related fields. As a very promising technology for high-quality displays and energy-saving lighting, white OLEDs (WOLEDs) have vastly attracted both industrial and academic interest [39-41]. Since the first white organic light-emitting diode (WOLED) reported by Kido et al. in 1994 with a PE of $0.83 \mathrm{~lm} \mathrm{~W}^{-1}$ [42,43], the performance of WOLEDs has been significantly improved during the last two decades. For example, phosphorescent WOLEDs can exhibit a PE $>120 \mathrm{~lm} \mathrm{~W}^{-1}$ in the revealed literature [44], the lifetime of fluorescent WOLEDs exceeds 150,000 h at $1000 \mathrm{~cd} \mathrm{~m}^{-2}$ [45], the luminance of hybrid WOLEDs overtakes $100,000 \mathrm{~cd} \mathrm{~m}^{-2}$ [46], the color rendering index (CRI) of WOLEDs are able to be higher than 90 [47-50], the correlated color temperature (CCT) of WOLEDs can mimic that of sunlight (2500-8000 K) [51-54], the color stability of WOLEDs are extremely stable without the change of Commission International de L'Eclairage (CIE) chromaticity coordinates [55-57].

Generally, the PE of $40-70 \mathrm{~lm} \mathrm{~W}^{-1}$ as well as the lifetime of $\geq 10,000 \mathrm{~h}$ at $\geq 1000 \mathrm{~cd} \mathrm{~m}^{-2}$ are required for the commercial applications of WOLEDs [1-5]. In terms of various applications, the requirements for WOLEDs are different. For instance, for displays, the color of WOLEDs should be very close to the white-equivalent point of $(0.33,0.33)$ [58]. However, for lighting, the most important reference light source is the warm white standard illuminant A with a CIE coordinates of $(0.445,0.405)$ and CCT of $2856 \mathrm{~K}$ [59-61]. Besides, if a WOLED shows a CIE coordinates nearby $(0.33,0.33)$, this emission is generally viewed as the white color (e.g., bluish white, or reddish white) [62-67]. Additionally, although the CRI is not crucial to displays, CRI it should be above 80 for indoor lighting. Moreover, since organic emitters usually have broad full wavelength at-half-maximum, high CRIs can be more easily achieved in WOLEDs than their counterparts (e.g., other kinds of LEDs) [68-71].

Nowadays, many approaches have been reported to develop high-performance WOLEDs, including managing singlet and triplet excitons for hybrid structures [72-75], harvesting triplets from blue fluorophors with high $\mathrm{T}_{1}$ [76-80], having charge- and exciton-confining structures to reduce the efficiency roll-off [81-83], combining blue/green/red phosphors with light-outcoupling enhancement techniques [84], adopting color down-conversion media [85], comprising ultrathin emitting layers (EMLs) [86-90], using tandem architectures [91-95], employing excimer systems [96-98], eliminating interlayer in hybrid WOLEDs [99,100], and exploiting double multifunctional blue EMLs [101]. Among them, the use of exciplexes in WOLEDs has been actively investigated, since exciplexes can be effectively functioned as (i) fluorescent or TADF emitters; (ii) the hosts of fluorescent, phosphorescent and TADF dopants [102-110]. At the early stage, the efficiency of exciplex-based WOLEDs is poor. With the understanding of TADF exciplexes [111], the performance of exciplex-based WOLEDs has been remarkably enhanced. As an excellent result, the PE of exciplex-based WOLEDs can be $>100 \mathrm{~lm} \mathrm{~W} \mathrm{~W}^{-1}$ [112], which is comparable to that of state-of-the-art WOLEDs. On one hand, when the exciplex is acted as an emitter, the molecular emitter is unnecessary. If the donor and acceptor of the exciplex are also used as the hole transport layer (HTL) and electron transport layer (ETL), respectively, the number of evaporation sources can be reduced. On the other hand, when the exciplex is functioned as the host, the charge balance in the EML can be well regulated by changing the ratio of the donor and acceptor. Besides, by selecting appropriate donor and acceptor materials, the energy difference between the exciplex host and guest can be small enough, and the energy level of the donor and acceptor can well match with the HTL and ETL, respectively. Therefore, the unique merits of exciplexes render that them have been aggressively investigated in WOLEDs.

Herein, the fundamental concepts of exciplexes and their use in OLEDs will be first introduced. Then, the primary strategies to develop exciplex-based WOLEDs will be concluded. In particular, representative WOLEDs using exciplex emitters or hosts will be emphasized. More specifically, the design strategy, device architecture, emission mechanism as well as electroluminescence (EL) 
procedure for exciplex-based WOLEDs will be presented. In the end, an outlook for the future development of exciplex-based WOLEDs will be proposed.

\section{Fundamental Concepts of Exciplex}

\subsection{The Generation of Exciplex}

When sequentially depositing the electron-donating groups of p-type materials and the electron-accepting groups of n-type materials in single layer or co-doping these two types of materials, two different kinds of excited-state complexes can be formed, namely exciplex and electroplex [113-115], as shown in Figure 1. However, it is deserved to point out that the combination of p-type and bipolar materials or the alliance of bipolar and n-type materials can also generate the excited-state complexes, if there is a large hole/electron barrier between the two different materials [116]. For the excited-state complex emission, it is furnished by the radiative electron transition from the lowest unoccupied molecular orbital (LUMO) level of the electron acceptor molecule to the highest occupied molecular orbital (HOMO) of the electron donor molecule. In the case of planar aromatic molecules, the donor and acceptor moieties constituting an exciplex are separated by a smaller distance $(\sim 0.3-0.4 \mathrm{~nm})$ than the constituents of an electroplex $(\sim 0.4-0.7 \mathrm{~nm})$ [117]. Therefore, the generation of exciplex or electroplex is determined by the by material structures. Since free charges are normally not formed by photoexcitation (only when dissociation of excited states is facile, e.g., in a good photoconductor), the electroplex emission can only be observed in the EL [118-120]. On the other hand, since the exciplex is readily generated through photoexcitation, the exciplex emission can be detected from both EL and photoluminescence (PL) spectra [121]. By dint of these differences, the exciplex and electroplex can be distinguished.

a)

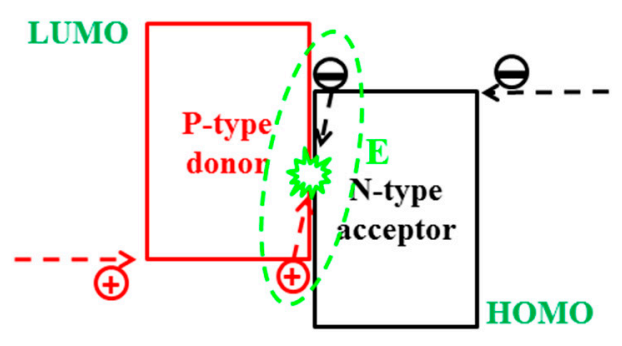

c)

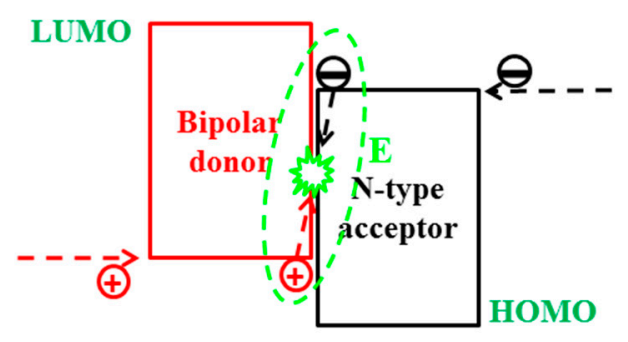

b)

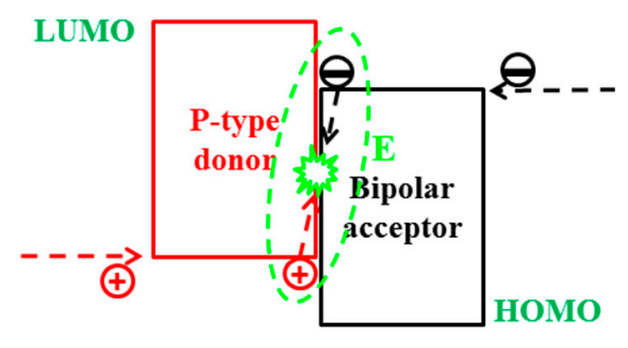

d)

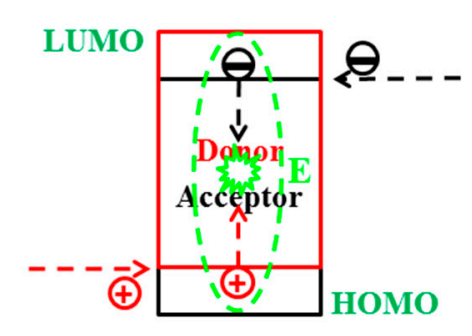

Figure 1. The diagram of formation exciplex or electroplex at the bilayer interface of p-type donor material and n-type acceptor material (a), p-type donor material and bipolar acceptor material (b), bipolar donor material and n-type acceptor material (c), co-doping donor and acceptor materials (d). E represents exciplex or electroplex, the black arrow and red arrow are electron and hole transporting, respectively. 


\subsection{The Recognition of Exciplex}

Before 2012, the efficiency of exciplex-based OLEDs is usually poor and the generation of exciplexes is considered as a negative factor to the performance. For exciplexes used in WOLEDs, the broad emission band of exciplexes are generally exploited to achieve high CRIs [122-124]. After the work demonstrated by Adachi et al. in 2012 [111], the performance of exciplex-based OLEDs has been accelerated, since it is recognized that exciplexes intrinsically possess small singlet-triplet energy gap $\left(\Delta_{\mathrm{EST}} \approx 0-0.1 \mathrm{eV}\right)$ and also allow high reverse intersystem crossing (RISC) efficiency [125-127].

In OLEDs, when holes meet electrons, singlets and triplets will be formed with a ratio of $1: 3$ due to the effect of spin statistics [128-130]. In the case of fluorescent emitters, singlets decay rapidly with the prompt nanoseconds fluorescence, whereas the radiative decay of triplets is spin forbidden [131-133]. In contrast, TADF emitters can also harvest triplets, because triplet excitons will be harnessed to produce the delayed fluorescence via an effective $T_{1} \rightarrow S_{1}$ RISC process [134-136]. In general, the $\Delta_{\text {EST }}$ $<0.2 \mathrm{eV}$ is required for TADF molecular design, which can prohibit the nonradiative decay channels and improve the up-conversion [137]. Therefore, same as phosphors, the theoretical unity IQE could be achieved [138-140]. Aside from pure TADF materials, exciplexes allow TADF emission via RISC due to the intrinsically small $\Delta_{\mathrm{EST}}$, resulting in 100\% IQE in exciplex-based OLEDs.

To attain efficient exciplexes, there are some predictions or guidelines have been reported: (i) the exciplex system and its resulting photon energy are predictable by using the solution redox potentials of the constituting molecules; (ii) a fundamental issue for high-efficiency exciplex-based OLEDs is achieving the high RISC efficiency; (iii) donor as well as acceptor molecules should possess high $\mathrm{T}_{1}$, which can not only be preferable for getting exciplex emitters with high fluorescence quantum yields, but also prohibit triplets quenching by confining the triplets of exciplexes from back energy transfer to donors and acceptors; (iv) high HOMO of donors and low LUMO of acceptors are significant; (v) an n-type material consisting of strong electron-withdrawing units and with low-lying LUMO energy is important; (vi) the balanced holes and electrons in the donor/acceptor heterojunction is desirable; (vii) the enhancement of the intermolecular contact can improve the light-emitting efficiency; and (viii) a broad exciton recombination zone can enhance the exciton utilization efficiency [111,125-127,141-145].

\section{Approaches for Exciplex-Based WOLEDs}

\subsection{Basic Aspects of Exciplex-Based WOLEDs}

According to the above concepts, two strategies have been proposed to apply exciplexes in WOLEDs, i.e., exciplexes are functioned as (i) fluorescent or TADF emitters; (ii) the hosts of fluorescent, phosphorescent and TADF dopants. Apart from the general issues to guarantee high-performance WOLEDs (e.g., the manipulation of charge injection, transport and balance, the management of exciton generation, harvesting, recombination, diffusion and quenching, the regulation of host (guest)-to-guest mutual energy transfer, and the enhancement of light outcoupling efficiency.) [146-156], some additional attentions are needed to be paid on the exciplex-based WOLEDs. On one hand, when using as the emitter, exciplexes give a new broad emission peak that appears at a long wavelength compared to the intrinsic donor and acceptor, which is beneficial to develop high-quality WOLEDs. For example, by using two exciplex emitters (merely complementary colors), Zhao et al. achieved a WOLED with a high CRI of 83 [157]. Besides, by utilizing the TADF mechanism and/or effective device engineering, all singlets/triplets generated in exciplex emitters could be harnessed, leading to highly efficient WOLEDs.

On the other hand, when using exciplex as the hosts, the voltage could be lower than that of conventional hosts since the injection/transport of electrons and holes are via the LUMO of acceptors and the HOMO of donors, respectively. Additionally, the approximately equal $\mathrm{S}_{1}$ and $\mathrm{T}_{1}$ of exciplexes makes it easy to adjust the energy level of exciplexes to that of emitter dopants by selecting appropriate donors and acceptors, which renders the energy transfer from both $\mathrm{S}_{1}$ and $\mathrm{T}_{1}$ of exciplex to that of the guests more easily. Hence, by designing efficient exciplexes and enhancing device engineering, 
exciplex-based WOLEDs are very promising for the lighting and displays. In the following sections, the design strategy, device architecture, emission mechanism as well as EL procedure for exciplex-based WOLEDs have been highlighted, including WOLEDs based on exciplex emitters or hosts.

\subsection{WOLEDs Based on Exciplex Emitters}

\subsubsection{WOLEDs Utilizing All Exciplex Emitters}

For WOLEDs utilizing all exciplex emitters, the combination of blue exciplex emission with complementary exciplex emission or green/red exciplex emissions is the most directed approach [158]. In such approach, blue, green, yellow, orange as well as red emitter is formed by exciplexes. Additionally, to enhance efficiency, it is more desirable to use TADF mechanism, since TADF exciplexes can harvest the triplet excitons. Otherwise, the triplets of exciplexes would be decayed nonradiatively, resulting in low performance.

In 2009, Zhu and coworkers adopted this way to develop WOLED via four exciplex emission bands, achieving very broad white-emission spectrum [159]. As shown in Figure 2, the device architecture is ITO $/ 4,4^{\prime}, 4^{\prime \prime}$-tris[methylpheny(phenyl)amino]-triphenylamine (m-MTDATA, $40 \mathrm{~nm}) /$ m-MTDATA: tris(dibenzoyl methane)-aluminum $\left(\mathrm{Al}(\mathrm{DBM})_{3}\right)(\mathrm{R}, \mathrm{x}) / \mathrm{N}, \mathrm{N}^{\prime}$-bis(3-methylphenyl)$\mathrm{N}, \mathrm{N}^{\prime}$-diphenylbenzidine (TPD): 4,7-diphenyl-1,10-phenanthroline (Bphen, $10 \mathrm{~nm}$ )/Bphen $(40 \mathrm{~nm}) / \mathrm{LiF}$ $(1 \mathrm{~nm}) / \mathrm{Al}(200 \mathrm{~nm})$, where $\mathrm{R}$ denotes the molar ratio of m-MTDATA-to-Al(DBM $)_{3}$ and $\mathrm{x}$ denotes its layer thickness. To regulate the spectra, $R$ was changed from $1: 1$ to $1: 2$ to $1: 3$, while $x$ was changed among $2,3,4$, and $5 \mathrm{~nm}$. In this device, white light is emitted by inserting two blend layers of m-MTDATA: $\mathrm{Al}(\mathrm{DBM})_{3}$ and TPD: Bphen between the m-MTDATA HTL and Bphen ETL. The white light spectrum consists of four broad bands that arise from blue-emitting TPD/Bphen $(463 \mathrm{~nm})$, green-emitting m-MTDATA/Bphen $(528 \mathrm{~nm})$, orange-emitting TPD/Al(DBM) $3(572 \mathrm{~nm})$, and red-emitting m-MTDATA/ $\mathrm{Al}(\mathrm{DBM})_{3}$ exciplexes $(650 \mathrm{~nm})$, respectively. These exciplex emissions are different from the PL spectra of m-MTDATA, TPD, Bphen, and $\mathrm{Al}(\mathrm{DBM})_{3}$ neat films, which give a monomer (i.e., bulk exciton) emission with peaks at about 375, 401, 413, and $425 \mathrm{~nm}$, respectively, as shown in Figure 2c. More specifically, the exciplex of m-MTDATA/Al(DBM $)_{3}$ is formed at the interface between m-MTDATA HTL and m-MTDATA: Al(DBM) $)_{3}$ layers, exciplexes of TPD/Al(DBM $)_{3}$ and m-MTDATA/Bphen are at the interface between m-MTDATA: $\mathrm{Al}(\mathrm{DBM})_{3}$ and TPD: Bphen layers, and the exciplex of TPD/Bphen is at the interface between TPD: Bphen and Bphen electron-transporting layers. The intralayer exciplexes of m-MTDATA/Al(DBM $)_{3}$ and TPD/Bphen are formed in m-MTDATA: $\mathrm{Al}(\mathrm{DBM})_{3}$ and TPD: Bphen layers, respectively. As a result, an ultrahigh CRI of 94.1 can be achieved. Although the current efficiency (CE) is low $\left(\sim 0.1 \mathrm{~cd} \mathrm{~A}^{-1}\right)$, such findings demonstrated a concept that high-quality white emissions can be generated without molecular emitters.

(a)

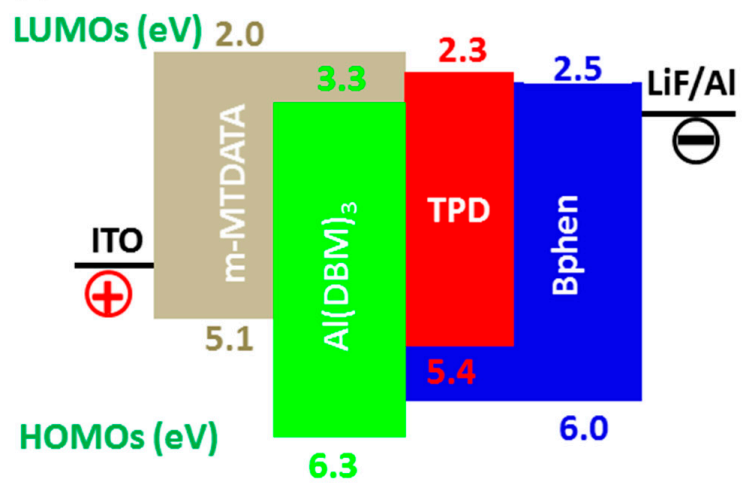

(b)

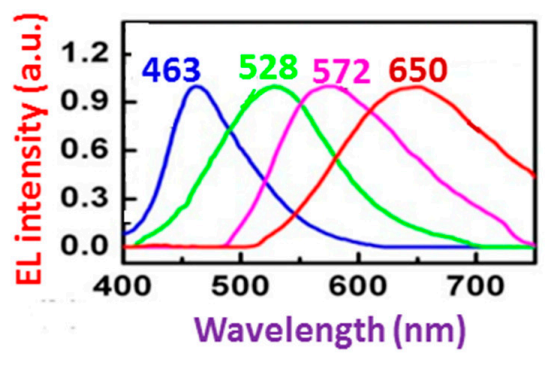

Figure 2. Cont. 
(c)

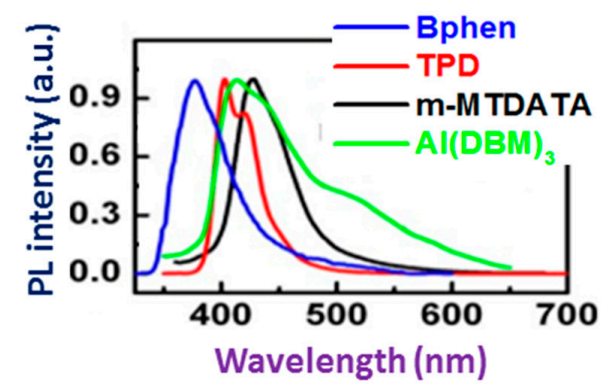

(d)

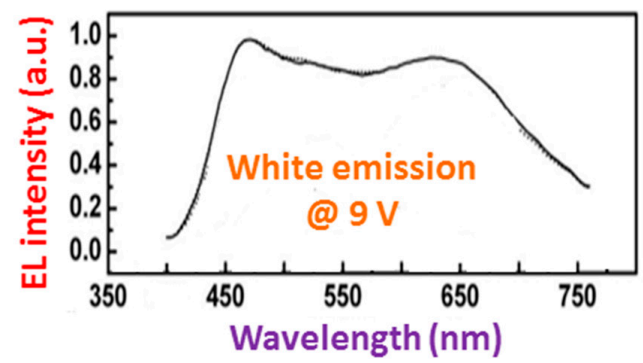

Figure 2. (a) Energy-level diagram of the white organic light-emitting diodes (WOLEDs). (b) Electroluminescence (EL) spectra of four organic light-emitting diodes (OLEDs): EL-1, EL-2, EL-3, and EL-4, where emission peaks appear at about 463, 528, 572, and $650 \mathrm{~nm}$, respectively. (c) Photoluminescence (PL) spectra of m-MTDATA, TPD, Bphen, and Al(DBM) $)_{3}$ films excited at $360 \mathrm{~nm}$. (d) EL spectrum of the WOLED with $\mathrm{x}=3 \mathrm{~nm}$ and $\mathrm{R}=1: 2$ at $9 \mathrm{~V}$ (Reproduced from [159]).

Currently, the utilization of tandem OLEDs, which refer to devices using charge generation layers (CGLs) or transparent conductive layers (e.g., ITO) to interconnect multiple EL units, has been considered to be an effective way to boost the performance [160-163]. Compared with single-unit OLEDs, the CE, EQE and lifetime of tandem OLEDs can be N-fold ( $\mathrm{N}$, the number of EL units) enhanced, since $\mathrm{N}$-fold luminance can be achieved with the current density similar to that of single-unit OLEDs. Therefore, tandem OLEDs have aroused both academic and industry interest. In terms of WOLEDs with all exciplex emitters, the introduction of exciplexes in each unit can be an effective scheme. Therefore, the molecular emitter is also unnecessary. For such approach, how to maximize the efficiency of the exciplex in each unit is crucial, apart from the design of efficient CGLs. Particularly, since it is relatively difficult to attain blue exciplexes, the development high-efficiency blue exciplexes is essential to the high performance [164].

In 2014, Hung et al reported the first tandem, all-exciplex-based WOLED, where blue and yellow exciplexes have been generated at each unit [165]. Figure 3 depicts the device architecture: ITO/polyethylene dioxythiophene: polystyrene sulfonate (PEDOT: PSS, $30 \mathrm{~nm}$ )/1,1-bis[(di-4-tolylamino)phenyl]cyclohexane (TAPC, $20 \mathrm{~nm}$ )/1,3-bis(N-carbazolyl)benzene (mCP, $15 \mathrm{~nm}) / \mathrm{mCP}:((1,3,5$-triazine-2,4,6-triyl)tris(benzene-3,1-diyl))tris(diphenylphosphine oxide) (PO-T2T) $(1: 1,20 \mathrm{~nm}) / \mathrm{PO}-\mathrm{T} 2 \mathrm{~T}(45 \mathrm{~nm}) / 8$-quinolinolato lithium (Liq, $1 \mathrm{~nm}) / \mathrm{Al}(1 \mathrm{~nm}) / \mathrm{MoO}_{3}$ (5 nm)/9,9-di[4-(di-p-tolyl)aminophenyl]fluorine (DTAF, $20 \mathrm{~nm}$ )/DTAF: PO-T2T (1:1, $20 \mathrm{~nm}$ )/PO-T2T $(50 \mathrm{~nm}) / \mathrm{Liq}(0.5 \mathrm{~nm}) / \mathrm{Al}(100 \mathrm{~nm})$, where the $\mathrm{CGL}$ is $\mathrm{DTAF} / \mathrm{MoO}_{3} / \mathrm{Al} / \mathrm{Liq}$ (holes and electrons are generated from the DTAF $/ \mathrm{MoO}_{3}$ interface), the blue and yellow exciplexes are formed from the blend of mCP: PO-T2T and DTAF: PO-T2T, respectively. The white light has been realized via the two parallel mixed layers, simultaneously producing yellow as well as blue exciplex light and hence a WOLED with a high EQE of $11.6 \%$. One of the reasons for the high performance is the development of a very efficient blue exciplex. To realize such high-energy blue exciplexes, (i) the acceptor has low HOMO (LUMO) for effective hole-blocking (electron injection) and high T1 for confining excitons of exciplexes; (ii) the acceptor exhibits the electron mobility which can be as high as the hole mobility for common HTLs. Hence, Hung et al. designed an acceptor PO-T2T with a T1 of $2.99 \mathrm{eV}$ and electron mobility of $1.7 \times 3.10^{-3}$ to $4.4 \times 10^{-3} \mathrm{~cm}^{2} \mathrm{~V}^{-1} \mathrm{~s}^{-1}$, meeting the above requirements [165]. As a result, the blue exciplex emission featured a low turn-on voltage of $2 \mathrm{~V}$, a maximum brightness of $24,600 \mathrm{~cd} \mathrm{~m}^{-2}$ and an EQE of $8.0 \%$, which is the best blue exciplex OLED at that time. By combining this efficient blue exciplex and yellow exciplex, the tandem WOLED has been demonstrated. Remarkably, the WOLED can exhibit a good color-stability, which is attributed to the avoidance of the movement of the charge recombination zone and elimination of the energy transfer between blue and yellow EMLs. 

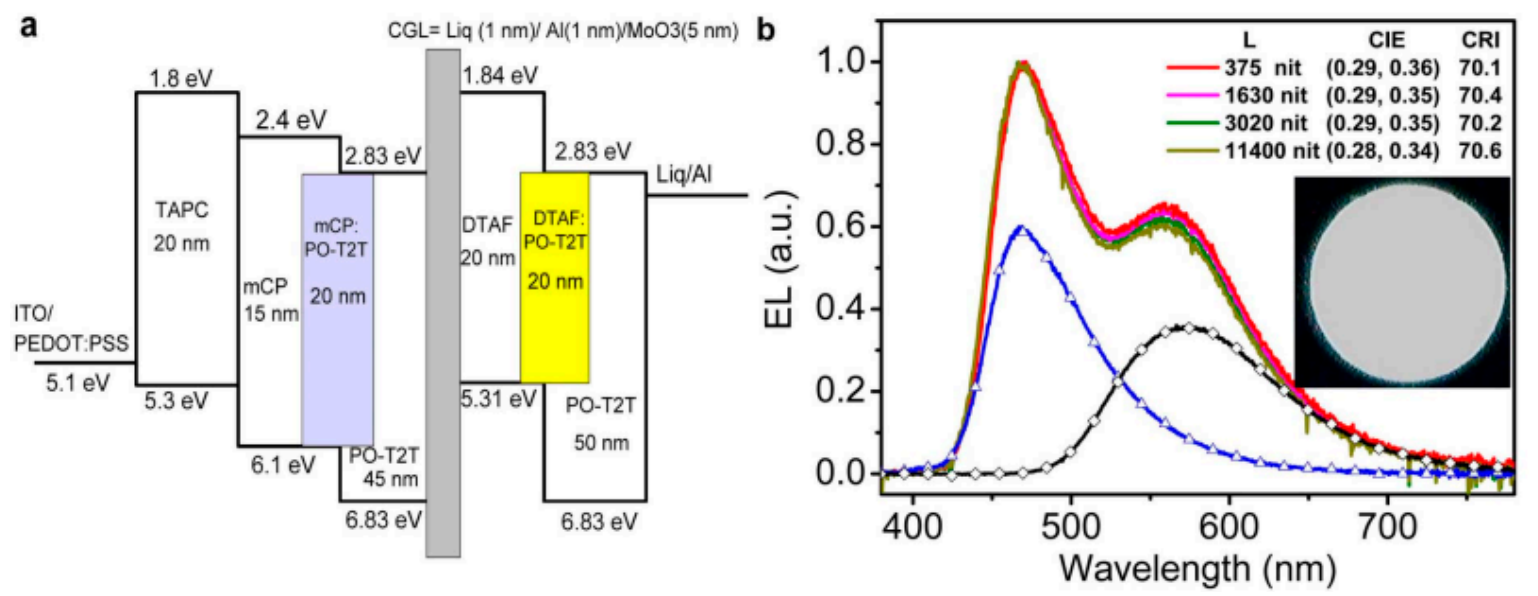

Figure 3. (a) The electronic level configurations of tandem WOLED. (b) EL spectra of the WOLED at different brightness, and two decomposed bands corresponding to the blue and yellow exciplex emissions [165].

\subsubsection{WOLEDs Combining Exciplex and Phosphorescent Emitters}

For WOLEDs combining exciplex and phosphorescent emitters, blue exciplex emitters are generally used to combine with phosphors, while other-color exciplexes are negligibly adopted. One of the reasons for this phenomenon may be attributed to the fact that it is not easy to synthesize efficient and stable blue molecular emitters, particularly for deep-blue ones. In contrast, by selecting appropriate donor and acceptor materials, high-performance blue exciplexes are promising to be the elegant emitters to organize WOLEDs. As a result, by incorporating blue exciplex with complementary or green/red phosphorescent emitters, high-performance WOLEDs can be established. For such WOLEDs, since blue light is originated from the blue fluorescence or TADF, they are also called hybrid WOLEDs [166]. Simply, this kind of hybrid WOLEDs can be classified into two types according to the use of blue exciplexes: hybrid WOLEDs with blue TADF exciplexes and hybrid WOLEDs with blue fluorescent exciplexes. In general, it is easy to understand that hybrid WOLEDs with blue TADF exciplexes can obtain high efficiencies, since the blue TADF exciplexes can harvest the triplets. However, by employing effective device engineering, hybrid WOLEDs with blue fluorescent exciplexes can also exhibit high performance, since the triplets of blue exciplexes which cannot be harnessed by the exciplexes can be harvested by the adjacent phosphorescent emitters (e.g., from the energy transfer and triplets diffusion mechanism) [167-169]. To fulfill these two types of hybrid WOLEDs, blue exciplexes are required to possess higher $\mathrm{T}_{1}$ compared with phosphorescent emitters, otherwise the triplets of phosphors would be quenched by the exciplex, leading to the poor performance. Particularly, it is deserved to note that the blue exciplexes are simultaneously functioned as the hosts in single-EML hybrid WOLEDs. In this case, the concentration of phosphorescent guest emitters is usually very low, which ensure the incomplete energy transfer from the blue exciplex host to the phosphorescent guests, otherwise only the guest emission can be produced.

In 2015, Zhang et al. explored a series of efficient WOLEDs, in which blue exciplexes have been combined with orange phosphorescent emitters, orange/red fluorescent emitters or orange TADF emitters [170]. By virtue of the blue TADF exciplex mCBP (donor): PO-T2T (acceptor), the energies have been transferred from the exciplex to orange fluorophor and phosphor dopants. For the double-EML hybrid WOLEDs combining blue exciplex and phosphorescent emitters, Figure 4 depicts the device structure: ITO/ $\mathrm{MoO}_{3}(3 \mathrm{~nm}) / 9,9^{\prime}$-biphenyl-3,3'-diylbis-9H-carbazole (mCBP, $20 \mathrm{~nm}$ )/mCBP: PO-T2T $(20 \mathrm{~nm}) / \mathrm{mCBP}:$ PO-T2T: $4.0 \mathrm{wt}$ \% $\%$ bis(2-phenyl-1,3-benzothiozolato-N,C2') iridium (acetylacetonate) $\operatorname{Ir}(\mathrm{bt})_{2}(\mathrm{acac})(2 \mathrm{~nm}) / \mathrm{PO}-\mathrm{T} 2 \mathrm{~T}(40 \mathrm{~nm}) / \mathrm{LiF} / \mathrm{Al}$. Since triplets of the exciplex were up-converted to $\mathrm{S}_{1}$ in a relatively long time, only part of triplets was converted as delayed fluorescence. Thus, the RISC efficiency has been less than unity. For extra triplets of the exciplex, they have been converted to heat 
and would harm the device via non-radiative decay. When a small concentration of orange phosphor has been doped or an adjacent orange phosphor doped layer has been presented, the extra triplets of the exciplex would incompletely transfer the energy to phosphors and finally contribute to the white light. Hence, the additional $2 \mathrm{~nm}$ orange EML renders an excellent warm WOLED with EQE of $22.21 \%$ and PE of $52.28 \mathrm{~lm} \mathrm{~W}^{-1}$. To simplify the structure, a single-EML hybrid WOLED was also developed by doping a low concentration $0.5 \mathrm{wt} . \%$ of $\operatorname{Ir}(\mathrm{bt})_{2}(\mathrm{acac})$ of in the full EML. The structure is ITO $/ \mathrm{MoO}_{3}(3 \mathrm{~nm}) / \mathrm{mCBP}(20 \mathrm{~nm}) / \mathrm{mCBP}:$ PO-T2T: $0.5 \mathrm{wt} . \% \operatorname{Ir}(\mathrm{bt})_{2}$ (acac) $(20 \mathrm{~nm}) / \mathrm{PO}-\mathrm{T} 2 \mathrm{~T}(40 \mathrm{~nm}) / \mathrm{LiF}$ $(0.8 \mathrm{~nm}) / \mathrm{Al}$. Due to the competition for the blue exciplex and phosphorescent guest, the single-EML WOLED showed a lower performance with a maximum PE of $39.89 \mathrm{~lm} \mathrm{~W}^{-1}$ and an EQE of $17.06 \%$.

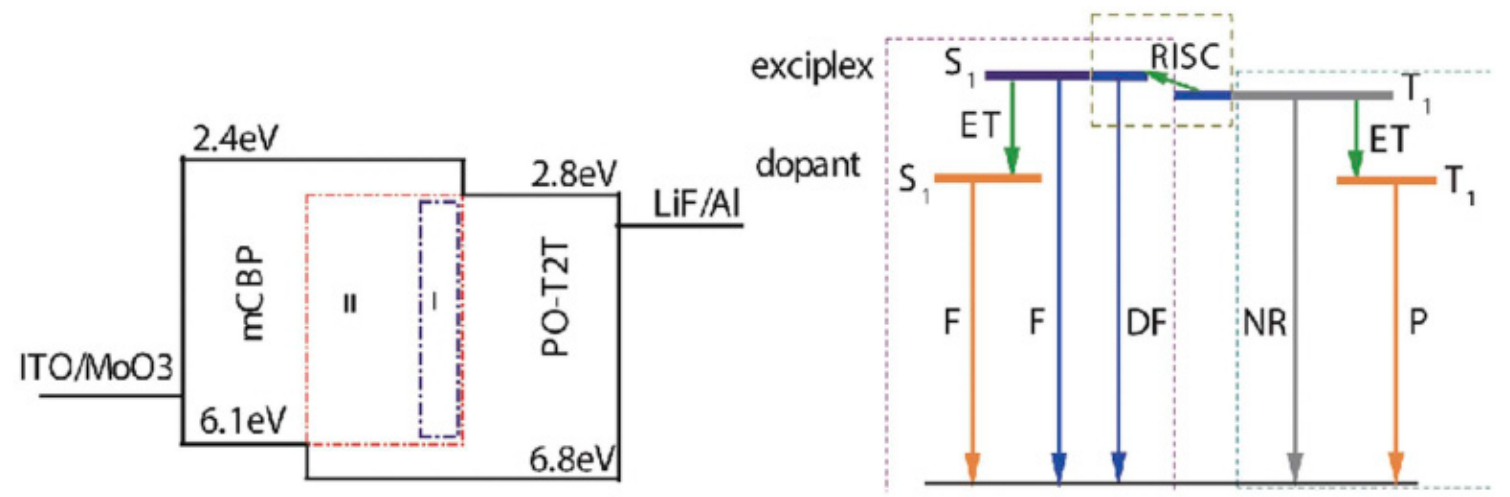

Figure 4. Device architecture of the WOLEDs and the incomplete energy transfer from blue exciplex to orange phosphor/fluorophor. Left: I and II indicate the dope areas of orange dopant, corresponding to WOLED with two EMLs and one EML. Right: incomplete energy transfer from exciplex to orange phosphor/fluorophor. F, DF, ET, NR and P denote fluorescence, delayed fluorescence, the part of triplet/singlet exciplex transfer its energy to the orange dopant, non-radiative process and phosphorescence, respectively [170].

In 2015, Liu et al. achieved an efficient blue exciplex host via (4-dimesitylboryl)phenyltriphenylamine (TPAPB) and 1,3,5-tri(1-phenyl-1H-benzo[d]imidazol-2-yl)phenyl (TPBi), exhibiting a PL quantum efficiency (PLQY) of $44.1 \%$, where the up-conversion of triplets to singlets is mainly via triplet-triplet annihilation (TTA) [109]. By doping an orange phosphor into this exciplex host, a single-EML hybrid WOLED exhibited a maximum EQE and PE of $15.7 \pm 0.3 \%$ and $29.6 \pm 0.2 \mathrm{~lm} \mathrm{~W} \mathrm{~W}^{-1}$, respectively. Then, their group realized single-EML hybrid WOLEDs with blue TADF exciplexes by using a low phosphor guest concentration to ensure the incomplete energy transfer, in which the blue emission was resulted from the TADF exciplex host 4,4'-bis(9-carbazolyl)-2,2'-dimethylbiphenyl (CDBP): PO-T2T [171]. Due to the efficient exciplex and well management of excitons, the WOLED shows the maximum EQE and PE of $25.5 \%$ and $84.1 \mathrm{~lm} \mathrm{~W}^{-1}$, respectively.

Furthermore, to improve performances of such kind of WOLEDs, Wu and coworkers also used the blue exciplex CDBP: PO-T2T to manage exciton allocation [172]. By doping iridium(III) bis(4-phenylthieno[3,2-c]pyridinato-N,C2') acetylacetonate (PO-01) into the CDBP: PO-T2T host, their device having triple EMLs exhibited the peak EQE and PE as high as $28.3 \%$ and $102.9 \mathrm{~lm} \mathrm{~W}^{-1}$, respectively. Even at $1000 \mathrm{~cd} \mathrm{~m}^{-2}$, the efficiencies were very impressive $\left(25.8 \%\right.$ and $\left.63.5 \mathrm{~lm} \mathrm{~W}^{-1}\right)$, which are the highest among hybrid WOLEDs with blue exciplexes.

For hybrid WOLEDs with blue fluorescent exciplexes, Luo et al. reported this method by using 1,3,5-tri(m-pyrid-3-yl-phenyl)benzene (TmPyPB) as an acceptor while TAPC as a donor [173]. Aside from the exciplex, electroplex can also be produced from the TAPC/TmPyPB interface, rendering that the blue emission is very broad, which is beneficial to yield white light. By taking advantage of the doping-free technology, single-molecular-emitter based WOLEDs (WOLED-I) showed an EQE as high as $16.8 \%$. Besides, two-molecular-emitter WOLEDs (WOLED-II) possessed high EQE (15.1\%), high CRI 
(92.1) and low CCT (2319 K). For their device architectures, the main difference between WOLED-I and WOLED-II is the used EMLs. For example, only $0.3 \mathrm{~nm}$ doping-free yellow phosphorescent EML bis(2-phenyl-4,5-dimethylpyridinato)[2-(biphenyl-3-yl)pyridinato] iridium(III) [Ir(dmppy) 2 (dpp)] has been adopted in WOLED-I, while additional $0.3 \mathrm{~nm}$ doping-free red phosphorescent EML tris(1-phenylisoquinolinolato-C2,N) iridium(III) $\left[\operatorname{Ir}(\mathrm{piq})_{3}\right]$ and the $0.3 \mathrm{~nm} \operatorname{Ir}(\mathrm{dmppy})_{2}(\mathrm{dpp})$ have been placed both sides of the TAPC/TmPyPB system in WOLED-II. Besides, it is deserved to point out that the thin EMLs are conducive to avoid the concentration quenching, ensuring the high performance. Further working mechanism for WOLED-I and WOLED-II can be seen in Figure 5 . In both WOLED-I and WOLED-II, the blue light has been generated by the TAPC/TmPyPB system. For the complementary light in WOLED-I, it could be originated from the TAPC/TmPyPB system. Besides, triplet excitons of the TAPC/TmPyPB system, the donor TAPC and the acceptor TmPyPB could be harvested by $\operatorname{Ir}(\mathrm{dmppy})_{2}(\mathrm{dpp})$ by dint of diffusion mechanism. Furthermore, the direct exciton formation on $\operatorname{Ir}(\mathrm{dmppy})_{2}$ (dpp) via the tunneling effect also contributed to the yellow emission. For WOLED-II, the working mechanism of yellow light was similar to that of WOLED-I. However, due to the fact that a part of excitons have been harnessed by the red phosphor, excitons managed by yellow as well as blue has been relatively reduced in WOLED-II. In addition, singlet and triplet excitons could be more readily harnessed via the red phosphor compared with the yellow phosphor, since the red phosphor has been set in a place that it is more closed to the exciton generation zone.

a)

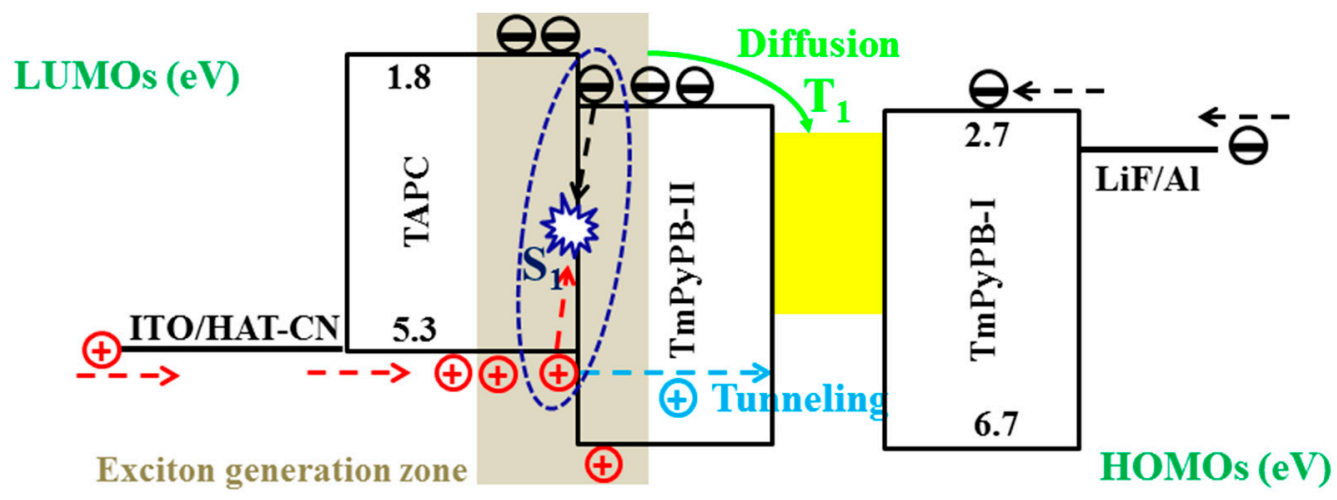

b)

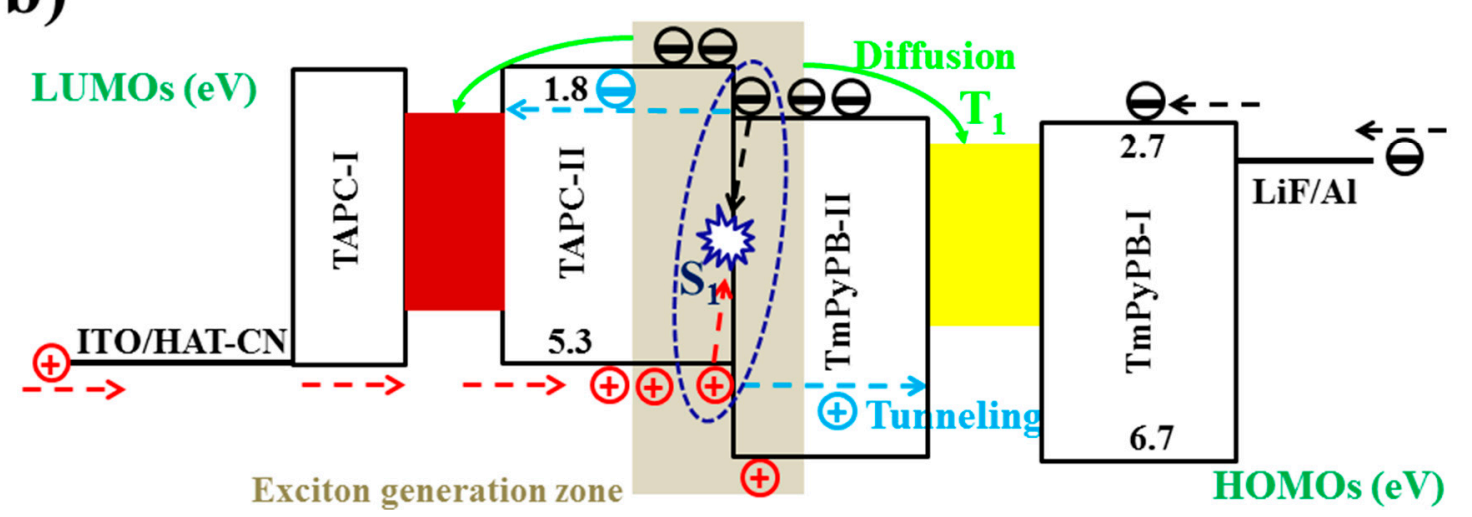

Figure 5. Working mechanisms for (a) WOLED-I; (b) WOLED-II [173].

\subsubsection{WOLEDs Using Exciplex and TADF Emitters}

Similar to phosphorescent emitter, the TADF emitter could harness both singlets and triplets. Therefore, by combining TADF emitter and exciplex, it can be another scheme to develop high-performance WOLEDs. Grybauskaite-Kaminskiene et al. combined TADF emitter 4,4'-(9H,9' H-[3,3'-bicarbazole]-9,9'-diyl)bis(3-(trifluoromethyl)benzonitrile) ( $\left.\mathrm{pCNBCzoCF}_{3}\right)$ showing blue 
emission with the orange exciplex emission from $\mathrm{pCNBCzoCF}_{3} / 4,4^{\prime}, 4^{\prime \prime}$-tris[phenyl(m-tolyl)amino] triphenylamine (m-MTDATA) interface, fabricating highly efficient "warm-white" OLEDs with a maximum EQE of $18.8 \%$ and $19.3 \mathrm{~lm} \mathrm{~W}^{-1}$, respectively [174]. Besides, Luo et al. reported an extremely simple but high-performance WOLEDs [175]. For their device, the high-quality white light could be achieved via only single molecular emitter. More specifically, the doping-free $\mathrm{p}$-i-n WOLED has been formed by sandwiching the intrinsic TADF material between p-type transporting layer and n-type transporting layer, achieving high-quality white light with the CRI as high as 91. Besides, a peak total PE and EQE as high as $68.5 \mathrm{~lm} \mathrm{~W} \mathrm{~W}^{-1}$ and $28.4 \%$ could be obtained. As shown in Figure 6, $40 \mathrm{~nm}$ TAPC and $55 \mathrm{~nm}$ TmPyPB have been selected to be p-type transporting layer and n-type transporting layer for the p-i-n WOLED, respectively. Besides, $2 \mathrm{~nm}$ 9,9', $9^{\prime \prime}, 9^{\prime \prime \prime}$-((6-phenyl-1,3,5-triazine-2,4-diyl)bis(benzene-5,3,1-triyl))tetrakis(9H-carbazole) (DDCzTrz) has been used to be TADF EML. As a result, the three-layer structure of TAPC/DDCzTrz/TmPyPB has been formed. Besides, ITO/ $\mathrm{MoO}_{3}$ and $\mathrm{LiF} / \mathrm{Al}$ have been used to be anode and cathode, respectively, ensuring that holes and electrons could be effectively injected. The emission mechanism for white light was to simultaneously produce the blue TADF light which was originated from the TADF emitter DDCzTrz and the exciplex emission which was generated from the p-type layer TAPC (donor) and DDCzTrz (acceptor). Besides, both $\mathrm{S}_{1}$ and $\mathrm{T}_{1}$ of the exciplex are lower than those of TAPC and DDCzTrz (e.g., the $\mathrm{T}_{1}$ of TAPC and DDCzTrz are 2.87 and $2.53 \mathrm{eV}$, respectively), suggesting that excitons on the exciplex would not be quenched by the donor and acceptor, ensuring the efficient orange light otherwise the exciton leakage would deteriorate the performance.

(a)
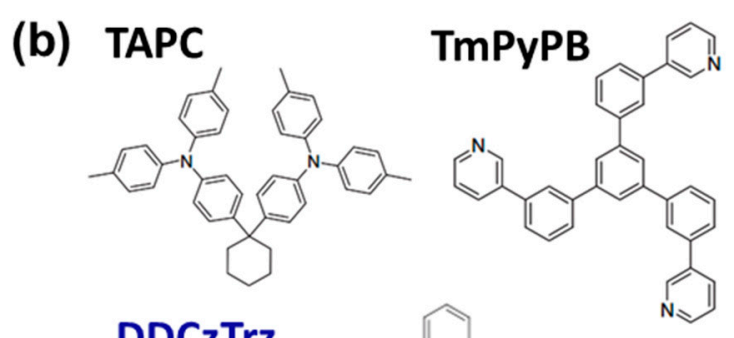

(c)
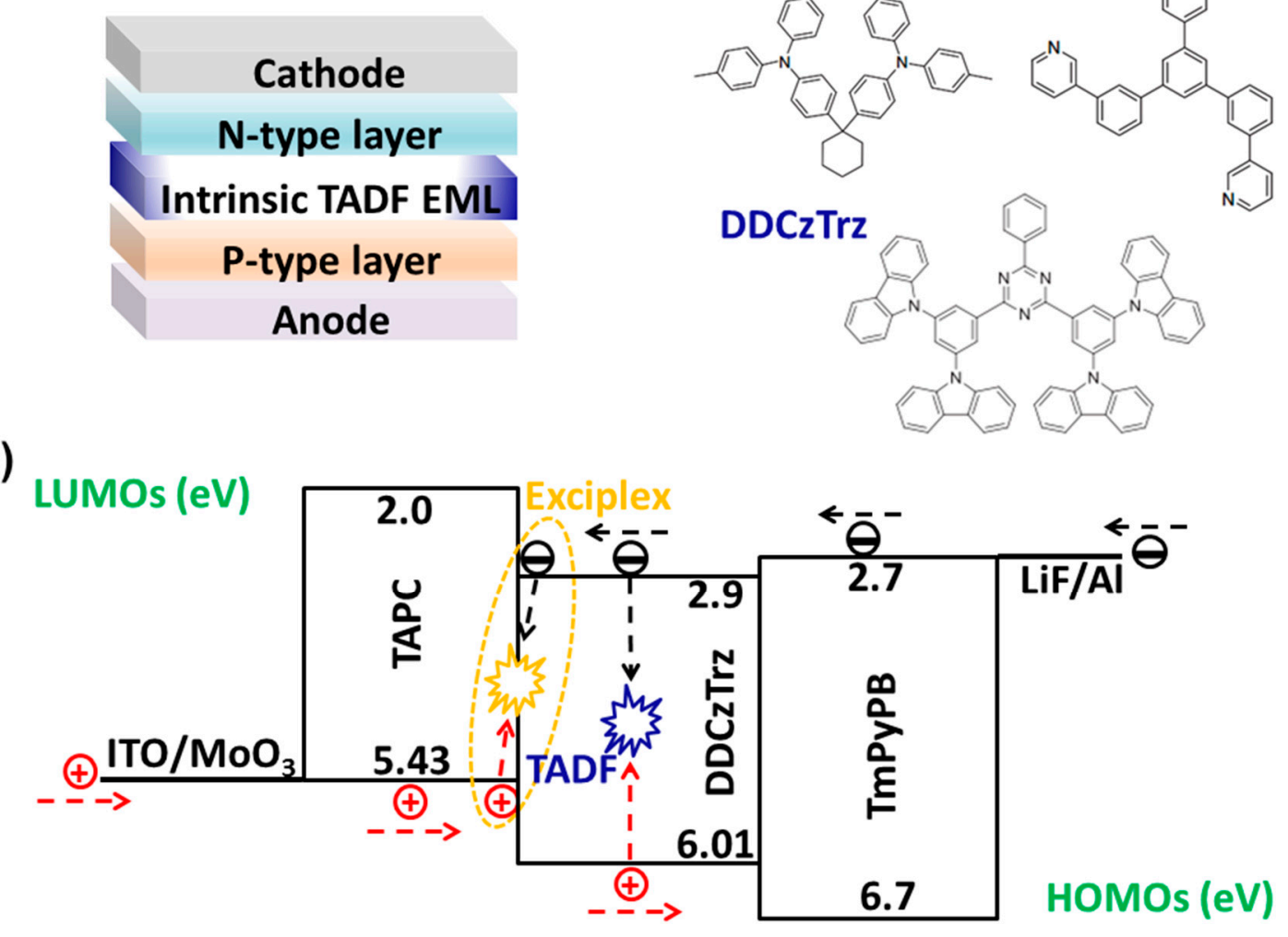

Figure 6. (a) The device architecture for p-i-n WOLEDs. (b) Molecular structures of TAPC, TmPyPB and DDCzTrz. (c) The working mechanism. The red arrow and black arrow are the hole and electron flow, respectively [175]. 


\subsubsection{WOLEDs Exploiting Exciplex and Fluorescent Emitters}

To achieve high-efficiency WOLEDs exploiting exciplex and fluorescent emitters, it is required that the exciplex emitter can well take advantage of the TADF mechanism to harvest the triplets via the RISC procedure, since the fluorescent emitters cannot make use of the triplets. In such way, single-EML structures are more easily to manipulate the excitons distribution. Similar to single-EML hybrid WOLEDs with blue exciplex hosts, the exciplexes are simultaneously functioned as the blue emitter and the host of fluorescent guest emitter in single-EML WOLEDs exploiting exciplex and fluorescent emitters. Thus, the concentration of fluorescent guest emitters is also low to ensure the incomplete energy transfer from the blue exciplex host to the fluorescent guests via the Förster energy transfer [176].

In Wu's work, they also realize the WOLED by exploiting exciplex and fluorescent emitters [172]. They have developed a single-EML fluorescent WOLED by doping a low concentration of $0.3 \%$ 2,8-di-tert-butyl-5,11-bis(4-tert-butylphenyl)-6,12-diphenyltetracene (TBRb) complementary guest in the blue exciplex CDBP: PO-T2T host, achieving the maximum EQE and PE as high as $20.8 \%$ and $75.4 \mathrm{~lm} \mathrm{~W} \mathrm{~W}^{-1}$, respectively. For the emission mechanism, the incomplete energy transfer ensured that the blue light could be generated by the exciplex host while the complementary light by TBRb, where the energy transfer is Förster type rather than Dexter type due to the low concentration of TBRb, as displayed in Figure 7. In addition, exciplex host has the low HOMO of donor and high LUMO of acceptor, which reduce the guest trapping effect, yielding the nearly unity of exciton utilization ratio.

a
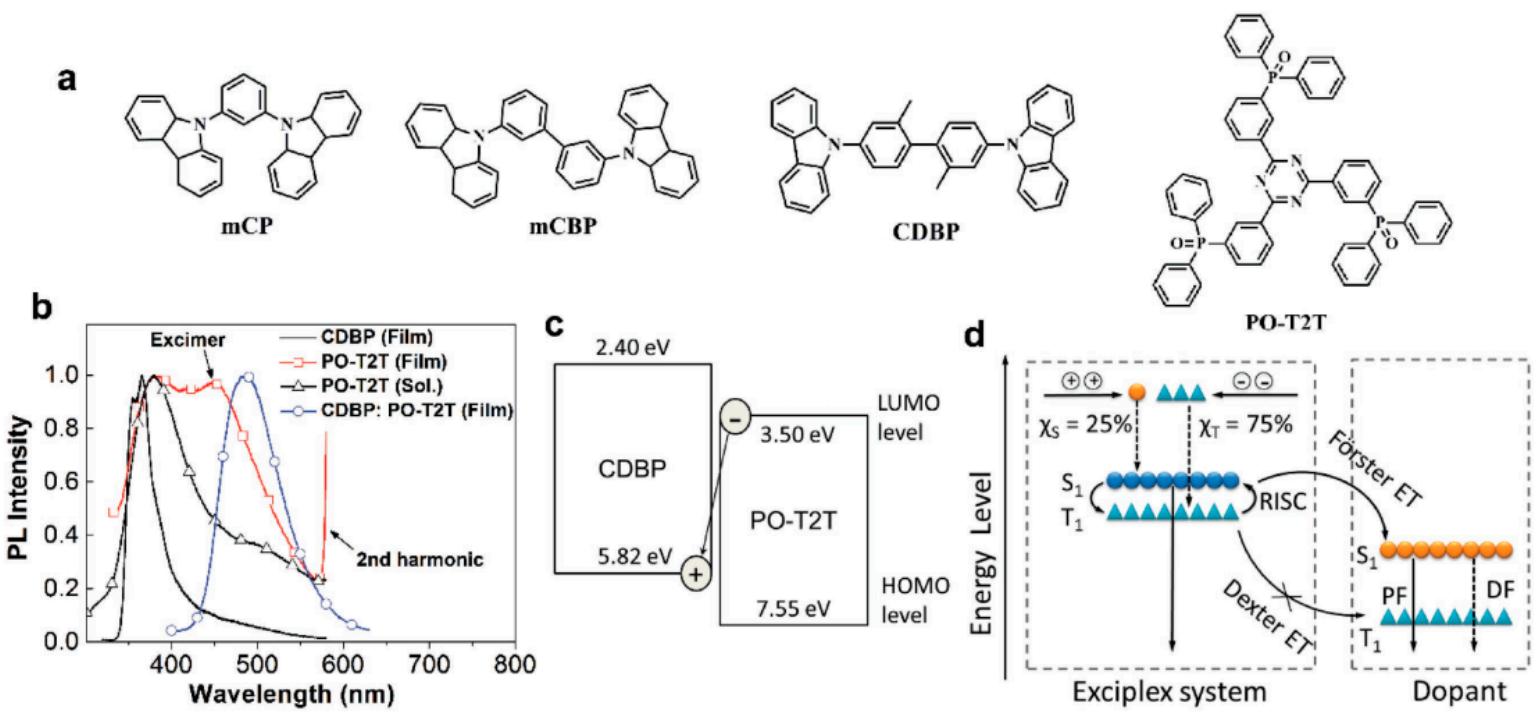

Figure 7. (a) Molecular structures of $\mathrm{mCP}, \mathrm{mCBP}, \mathrm{CDBP}$ as well as PO-T2T. (b) The PL spectra for CDBP film (solid line), PO-T2T film (line with square), PO-T2T solution (line with triangle), and CDBP: PO-T2T co-deposited film (line with circle). (c) The exciplex light generated from the donor CDBP and acceptor PO-T2T. (d) Physical processes in the exciplex host-dopant systems. ET, PF and DF are energy transfer, prompt fluorescence, and delayed fluorescence, respectively [172].

\subsection{WOLEDs Based on Exciplex Hosts}

\subsubsection{The Understanding of WOLEDs Based on Exciplex Hosts}

In general, the $\Delta_{\mathrm{EST}}$ of exciplexes is lower compared with the intramolecular excited state, because distance between HOMO and LUMO in exciplexes is larger [177]. Hence, exciplexes can obtain the unity IQE by virtue of the RISC procedure due to the small $\Delta_{\mathrm{EST}}$. To take advantage of exciplex, another strategy is using exciplex as the host of emitters. To accomplish such strategy, the guest emitters can be phosphorescent, TADF or fluorescent materials. Particularly, since fluorescent emitters 
are unable to harvest triplets, TADF exciplex hosts are necessary to guarantee the high efficiency of WOLEDs comprising exciplex as the host of fluorescent emitters. For this way, single-EML structures are usually utilized, since it is easy to lower the number of fluorescent molecules in single-EML WOLEDs. Generally, by using guests with low concentrations, the exciplex hosts also functioned as the blue emitters via the incomplete energy transfer, as introduced in the Section 3.2.4.

Besides, since holes and electrons are transported from the HOMO of donors and the LUMO of acceptors, respectively, low voltages can be obtained. Furthermore, by choosing suitable donors and acceptors, energy levels of the exciplex can be easily adjusted to meet guests owing to the approximately equal $S_{1}$ and $T_{1}$ of exciplex. Therefore, by using exciplex as the host, it can be effective to realize high-performance devices. By combining high- $\mathrm{T}_{1}$ donor and acceptor, the exciplex is possible to possess high $\mathrm{T}_{1}$. If the blue phosphorescent or TADF guests show a lower $\mathrm{T}_{1}$ than exciplexes, the exciplexes could be used as hosts to achieve high-performance WOLEDs. Generally, it is promising for the TADF exciplex to satisfy the demand of high $\mathrm{T}_{1}$ [112]. Hence, when TADF exciplex hosts have been adopted, (i) the issue of carrier injection barrier can be eliminated, (ii) the RISC process can be efficient, (iii) the exciton leakage can be prevented by reducing the guest-host $\mathrm{T}_{1}$ back energy transfer. As a consequence, by using TADF exciplex hosts in WOLEDs, it is possible to simultaneously realize high efficiencies, reduced voltages and efficient exciton confining. For this approach, it is required that $\mathrm{T}_{1}$ of the exciplex should be lower compared with the donor as well as acceptor, which is helpful to avert the triplet exciton quenching.

By using exciplexes as the host of phosphorescent emitters and TADF emitters, the concentration of the dopants is relatively high, which is beneficial for dopants to harvest the excitons on the exciplex host since the distance between host and dopants is decreased. Besides, if high concentration were used, excitons can be directly formed on the dopants, which also can be fully harvested by phosphorescent or TADF emitters. Hence, high efficiency can be guaranteed. However, by exploiting TADF exciplexes as the host of phosphorescent or TADF emitters, there is no need to use dopants with high concentrations. This is because the triplets on the host can be up-converted to singlets via the RISC process, and then the energy can be transferred to guests via the long-distance Förster procedure, leading to the high efficiency.

\subsubsection{WOLEDs Employing Exciplex as the Host of Phosphorescent Emitters}

Since the $\mathrm{T}_{1}$ of blue phosphorescent emitters is usually very high (e.g., $2.62 \mathrm{eV}$ for iridium(III) bis[(4,6-difluorophenyl)-pyridinato-N,C2']-picolinate (FIrpic)) [178-180], the exciplex host should possess high $\mathrm{T}_{1}$ to confine the excitons. Hence, for WOLEDs employing exciplex as the host of phosphorescent emitters, how to select a high- $\mathrm{T}_{1}$ exciplex is critical. Wang et al. realize this kind of WOLED by adopting the exciplex showing the high $\mathrm{T}_{1}(2.97 \mathrm{eV})$ formed by $\mathrm{mCP}$ : bis-4,6-(3,5-di-3-pyridyl-phenyl)-2-methylpyrimidine (B3PYMPM) as the host for FIrpic, and inserting an ultrathin nondoped PO-01 as the orange EML [181]. As a result, the WOLED exhibits maximum forward-viewing efficiencies of $20.0 \%$ and $75.3 \mathrm{~lm} \mathrm{~W}^{-1}$. Even at $1000 \mathrm{~cd} \mathrm{~m}^{-2}$, the efficiencies could be as high as $19.5 \%$ and $63.1 \mathrm{~lm} \mathrm{~W}{ }^{-1}$. As displayed in Figure 8 , the device architecture is $\mathrm{ITO} / \mathrm{MoO}_{3}$ $(10 \mathrm{~nm}) /$ TAPC: $\mathrm{MoO}_{3}(10 \%, 50 \mathrm{~nm}) /$ TAPC $(20 \mathrm{~nm}) /$ PO-01 $(0.06 \mathrm{~nm}) / \mathrm{mCP}:$ B3PYMPM: FIrpic (1:1:0.4, $10 \mathrm{~nm}) /$ B3PYMPM (15 nm)/B3PYMPM: $\mathrm{Li}_{2} \mathrm{CO}_{3}(3 \%, 40 \mathrm{~nm}) / \mathrm{Li}_{2} \mathrm{CO}_{3}(1 \mathrm{~nm}) /$ Al. Since TAPC possesses better hole mobility $\left(1.0 \times 10^{-2} \mathrm{~cm}^{2} \mathrm{v}^{-1} \mathrm{~s}^{-1}\right)$ and higher $\mathrm{T}_{1}(2.98 \mathrm{eV})$ compared with $\mathrm{mCP}$, it is key to the performance of the WOLED. The factors of the high performance could be summarized: (i) a good exciton confining EML structure has been formed via the large band gap hole transport and electron transport materials with high $\mathrm{T}_{1}$, (ii) the exciplex host could harness all excitons and transfer energy from both $\mathrm{S}_{1}$ and $\mathrm{T}_{1}$ to the dopants, (iii) the hole transport along HOMO of $\mathrm{mCP}$ and the electron transport along LUMO of B3PYMPM lower the electrical excitation energy, (iv) ultrathin PO-01 had a negligible effect on carrier transport, reducing the voltages, (v) p-doping HTL and n-doping ETL could further ensure the low voltage and high efficiency. For the emission mechanism, the FIrpic emission and PO-01 emission have been mainly resulted from energy transfer procedures. Specifically, holes 
and electrons have been first formed singlets as well as triplets on the exciplex host, then the energy of generated excitons has been transferred to FIrpic molecules, resulting in blue light. In addition, the energy of generated excitons on the exciplex host and FIrpic molecules could be transferred to PO-01 molecules, leading to orange light.

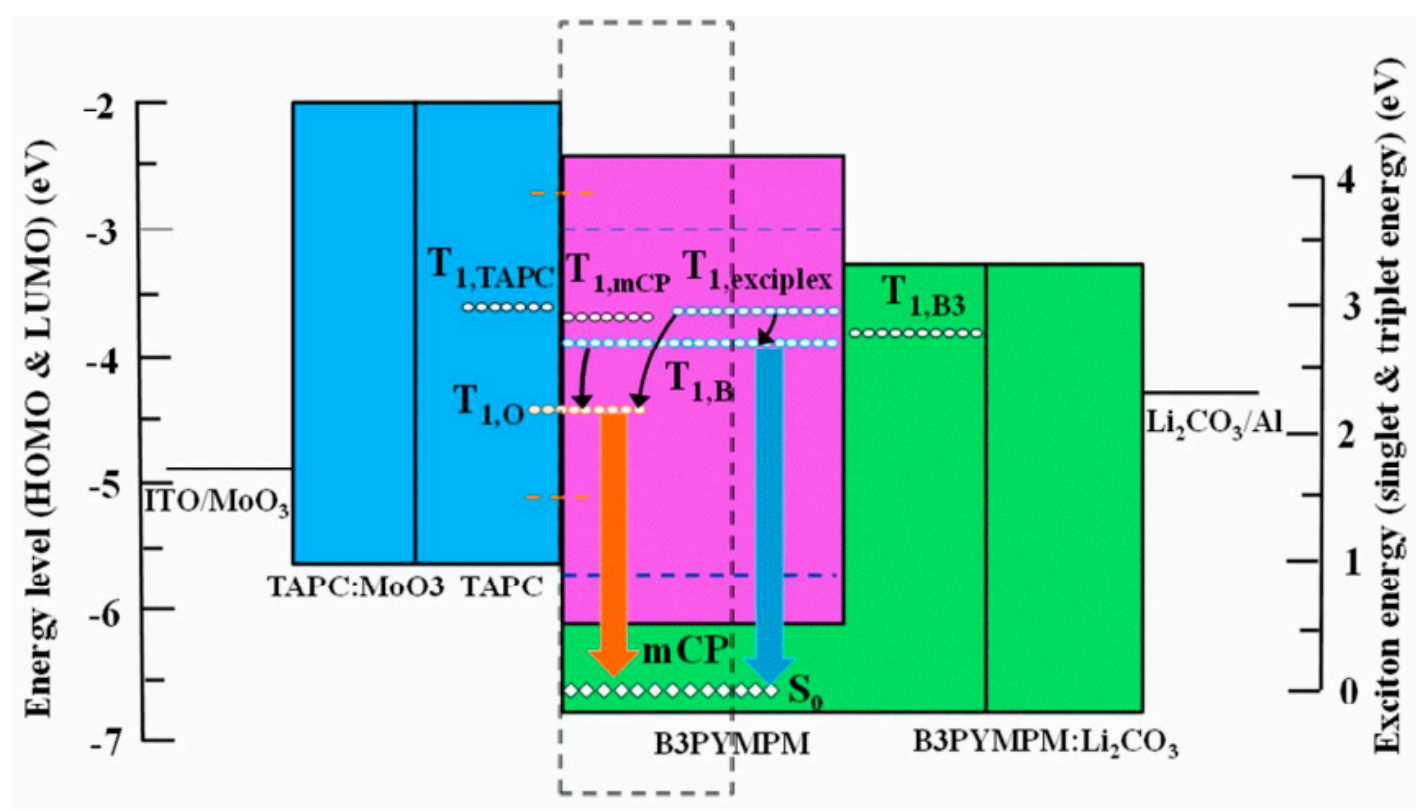

Figure 8. Device structure and energy levels. Black dashed rectangle is the main exciton recombination zone. O, B, and B3 are PO-01, FIrpic, and B3PYMPM, respectively. Solid and dashed lines correspond to the highest occupied molecular orbital (HOMO) and lowest unoccupied molecular orbital (LUMO) energy levels. Circles and diamonds are $T_{1}$ and $S_{0}$ exciton energies, respectively [181].

Furthermore, $\mathrm{Wu}$ et al. enhanced the performance of this kind of WOLED, achieving the EQE/PE as high as $28.1 \% / 105.0 \mathrm{~lm} \mathrm{~W}^{-1}$ [112]. For their exciplex host, $\mathrm{mCP}$ and 4,6-bis[3,5-(dipyrid-4-yl)phenyl]-2-methylpyrimidine (B4PyMPM) have been used as the donor and acceptor, respectively. Hence, by doping $15 \mathrm{wt} . \%$ FIrpic blue phosphor and low concentration of yellow phosphor PO-01 (0.2 wt.\%) into this exciplex system, highly efficient WOLEDs have been obtained. Particularly, their TADF exciplex host is significant, since (i) the heterogeneity is reduced via energy-matching HTL/ETL; (ii) the voltage is lowered due to the excellent charge mobilities (e.g., $5 \times 10^{-4}$ and $1 \times 10^{-4} \mathrm{~cm}^{2} \mathrm{~V}^{-1} \mathrm{~s}^{-1}$ for mCP and B4PyMPM, respectively); (iii) high- $\mathrm{T}_{1}$ donor/acceptor eliminate exciton leakage. As a consequence, total singlets and triplets have been only harvested by FIrpic or PO-01 by virtue of the Dexter or Förster energy transfer, leading to $100 \%$ exciton use.

\subsubsection{WOLEDs Adopting Exciplex as the Host of TADF Emitters}

For WOLEDs adopting exciplex as the host of TADF emitters, it is favorable to develop TADF exciplex hosts by carefully selecting donor and acceptor materials. Thus, by virtue of Förster energy transfer, guest TADF emitters can effectively harvest the singlets of the exciplex hosts. In addition, the $T_{1}$ of the exciplex is needed to be lower than that of each exciplex host, which is conducive to avert the triplets being quenched by the exciplex. On the other hand, the TADF emitter is required to show a lower $\mathrm{T}_{1}$ compared with the exciplex. If the above requirements can be satisfied, it is promising to construct low cost, high efficiency, stable color WOLEDs.

Recently, Zhang et al. built such WOLED by adopting CDBP: PO-T2T as the TADF exciplex host of blue and red TADF emitters, achieving the peak EQE and PE as high as $19.2 \%$ and $46.2 \mathrm{~lm} \mathrm{~W}^{-1}$, respectively [182]. For their EML architecture, a low concentration of $1 \mathrm{wt} . \%$ red TADF material 
2,6-bis[4-(diphencylamino)phenyl]-9,10-anthracenedione) (AnbTPA) has been doped into the CDBP: PO-T2T TADF exciplex host as a red EML, while a concentration of $10 \mathrm{wt}$ \% blue TADF material 1,2-bis(carbazol-9-yl)-4,5-dicyanobenzene (2CzPN) has been doped into the CDBP: PO-T2T TADF exciplex host as a blue EML. Particularly, an interlayer formed by the CDBP: PO-T2T TADF exciplex host has been inserted between the red and blue EMLs, as displayed in Figure 9. The reasons for their high performance are summarized below. First, by using CDBP: PO-T2T as the exciplex host, the RISC was efficient, which could enhance the efficiency of such kind of WOLEDs. Besides, this exciplex possessed the appropriate HOMO and LUMO, which could help to effectively form "barrier-free" characteristic and reduce trapping effect of guests. Additionally, by changing the ratio of CDBP or PO-T2T, it could regulate and balance the charge injection and transport. Furthermore, the additional introduction of interlayer could well confine excitons, which is beneficial to stabilizing the colors. Due to $\sim 3 \mathrm{~nm}$ Förster radius, Förster energy transfer between the red and blue EMLs could be prevented by the introduced $6 \mathrm{~nm}$ CDBP: PO-T2T interlayer. Hence, their WOLED could balance charge transporting as well as render singlets/triplets being formed on the full EML region. As a consequence, the exciton distribution for red EML and blue EML kept the same at various luminances, leading to a stable color.

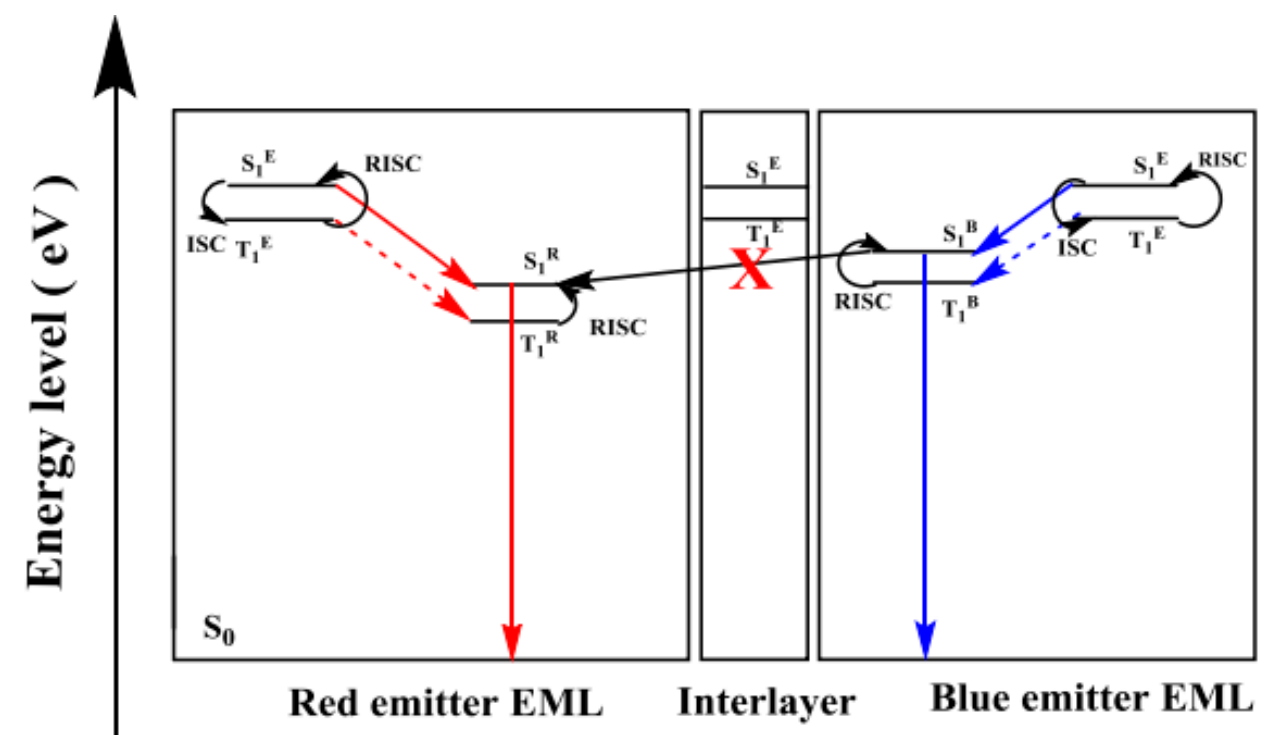

Figure 9. Exciton energies for exciplex hosts and decay channels for singlets as well as triplets. (Dash and solid arrows are Dexter and Förster energy transfer, respectively. The locking mark is singlets energy transfer stopping) [182].

\section{Summary and Outlook}

Since exciplexes can be (i) fluorescent or TADF emitters; (ii) the hosts of fluorescent, phosphorescent and TADF dopants, these excellent characteristics have rendered that exciplexes have been actively investigated in the WOLED. Currently, the efficiency for the exciplex-based WOLED can be comparable to that of other kinds of best WOLED. In this review, we have mainly focused on recent advances for the WOLED using exciplex emitters or hosts. Particularly, we have emphasized representative WOLEDs with all exciplex emitters, WOLEDs combining exciplex and phosphorescent emitters, WOLEDs using exciplex and TADF emitters, WOLEDs exploiting exciplex and fluorescent emitters, WOLEDs employing exciplex as the host of phosphorescent emitters and WOLEDs adopting exciplex as the host of TADF emitters. The detailed performances for exciplex-based WOLEDs have been described in Table 1. 
Table 1. Summarized performances for representative exciplex-based white organic light-emitting diodes (WOLEDs).

\begin{tabular}{|c|c|c|c|c|c|c|}
\hline WOLEDs a & $\begin{array}{c}V_{\text {on }} / 1000 \\
\text { (v) }\end{array}$ & $\begin{array}{c}\mathrm{EQE}_{\max } /_{1000}{ }^{\mathrm{c}} \\
\text { (External Quantum } \\
\text { Efficiency) (\%) }\end{array}$ & 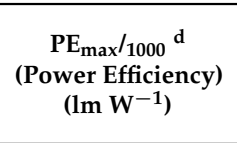 & $\begin{array}{c}\mathrm{CE}_{\max } /_{1000}{ }^{\mathrm{e}} \\
\left(\mathrm{cd} \mathrm{A} A^{-1}\right)\end{array}$ & $\begin{array}{c}\mathrm{CIE}^{\mathrm{f}} \\
\text { (Commission } \\
\text { International de } \\
\mathrm{L}^{\prime} \text { Eclairage) }\end{array}$ & $\begin{array}{c}\text { CRI g } \\
\text { (Color Rendering } \\
\text { Index) }\end{array}$ \\
\hline Ref. [112] & $2.5 / 3.6$ & $28.1 / 21.5$ & $105 / 59.5$ & $83.6 / 61.0$ & $(0.40,0.48)$ & - \\
\hline Ref. [159] & $\sim 2.0 /-$ & $-/-$ & $-/-$ & $0.1 /-$ & $(0.33,0.35)$ & 94.1 \\
\hline Ref. [165] & $4.0 / \sim 11$ & $11.6 / \sim 10$ & $15.8 / \sim 6$ & 27.7/- & $(0.29,0.35)$ & 70.6 \\
\hline Ref. [170] & $2.5 / 4.0$ & $22.21 / 20.56$ & $52.28 / 43.21$ & $58.35 / 54.01$ & $(0.418,0.433)$ & - \\
\hline Ref. [170] & - & $17.06 / 16.51$ & $39.89 / 33.25$ & $44.52 / 43.53$ & $(0.63,0.457)$ & - \\
\hline Ref. [171] & $2.5 /-$ & $25.5 / 14.8$ & $84.1 / 24.2$ & $67.0 / 37.0$ & $(0.40,0.43)$ & - \\
\hline Ref. [172] & $2.5 /-$ & $28.3 / 25.8$ & $102.9 / 63.5$ & $88.7 / 80.9$ & $(0.46,0.43)$ & 86 \\
\hline Ref. [172] & $2.6 /-$ & $20.8 /-$ & $75.4 /-$ & - & $(0.34,0.43)$ & - \\
\hline Ref. [173] & $-/-$ & $16.8 /-$ & $56.4 / 40.0$ & $49.6 /-$ & $(0.42,0.51)$ & 56 \\
\hline Ref. [175] & $3.0 /-$ & $28.4 / 3.9$ & $68.5 / 5.0$ & $65.4 / 8.7$ & $(0.34,0.35)$ & 91 \\
\hline Ref. [181] & $2.4 /-$ & $20.0 / 19.5$ & $75.3 / 63.1$ & $64.5 / 62.8$ & $(0.42,0.51)$ & - \\
\hline Ref. [182] & $2.5 /-$ & $19.2 /-$ & $46.2 /-$ & $36.7 /-$ & $(0.33,0.38)$ & 82 \\
\hline
\end{tabular}

Over recent years, the performance of exciplex-based WOLEDs has been step-by-step enhanced. In particular, their performance has been boosted after the recognition of exciplexes possessing TADF property. To date, there are still many challenges hindering the development of commercial productions, including the efficiency, efficiency roll-off, operational stability as well as color stability. For the issue of efficiency, since the theoretical efficiency limit of WOLEDs is $248 \mathrm{~lm} \mathrm{~W}^{-1}$, there is still much room for exciplex-based WOLEDs [183]. In OLEDs, the EQE is determined by outcoupling factor, carrier balance, fraction of excitons potentially decayed radiatively, as well as PLQY of materials. On the other side, the driving voltage can greatly affect PE. Hence, careful introduction for the donors and acceptors plays a significant role in exciplex-based WOLEDs. When the exciplex is used as the emitter, high PLQY of the exciplex is essential to the high performance, apart from the high RISC efficiency. Besides, regardless of WOLEDs based exciplex emitters or hosts, the elaborative management of the carrier and exciton distribution [184-188] as well as adoption of outcoupling technology [189-192] can improve efficiencies. Additionally, efficiency roll-off is somewhat serious, particularly for the WOLEDs using the TADF exciplex emitters. To overcome this issue, the charge balance, charge transport barriers and materials selection are required to be regulated, which are also beneficial to the color-stability [193-200]. Another possibility to affect fluorescence and phosphorescence of organic compounds is photonic structures, i.e., the photonic band gap (PhBG), which can manipulate the efficiency of OLEDs since PhBG is crucial for molding the propagation of light [201]. The periodic changes of refractive index within the colloidal crystal, i.e., crystal/voids, can cause a forbidden region of frequencies for photons, where the region is PhBG. Fluorescence can be influenced by the PhBG since fluorescence is the emission of an electromagnetic wave [202]. Particularly, in the Förster energy transfer process, PhBG can suppress the donor emission, which enhances the energy transfer, and in turn increases the acceptor emission. For example, the PhBG enhanced the Förster energy transfer efficiency from $37 \%$ to $61 \%$ [203]. On the other hand, phosphorescence emission can be obtained for forced intersystem crossing by engineering a PhBG (e.g., the phosphorescence was generated from bis(2-methyl-8-quinolinato)-4-phenylphenolate aluminum (BAlq)) [204].

In terms of the lifetime, it is a key factor to determine whether LEDs can meet the demand of the commercialization [205-208]. However, it is deserved to point out that exciplex-based WOLEDs have not yet achieved long lifetime. Hence, exciplex-based WOLEDs lag far behind other WOLEDs. For instance, the lifetime of hybrid WOLEDs can exceed $>30,000 \mathrm{~h}$ at $1000 \mathrm{~cd} \mathrm{~m}^{-2}$ [209]. Particularly, as "warm-white" OLEDs have recently demonstrated with high efficiency and stability [210-212], it may be helpful to develop exciplex-based WOLEDs based on this technology, enhancing their potential in the optoelectronic applications [213-215]. Therefore, more stable donor and acceptor 
materials should be urgently explored. Besides, much endeavors are needed to explore the stability mechanism of exciplex-based WOLEDs, which only receives negligible attention to date. After solving the mentioned issues, the prospect for mass production for exciplex-based WOLEDs will be bright.

Author Contributions: P.X., Y.Y., D.L. and B.L. conceived the idea; P.X., J.H., Y.Y., J.Y., D.L., D.L. and B.L. wrote the paper, B.L. advised the paper. All authors reviewed the paper.

Funding: The funding information is showed in the section of Acknowledgements.

Acknowledgments: The authors are grateful to the financial support from Scientific Research Starting Foundation of Foshan University (Grang Nos. Gg040926, 040973), the National Natural Science Foundation of China (Grant Nos. 11504050, 61704034), Foshan Science and technology innovation special funds (Grant No. 2017EZ100111), the Key Platforms and Research Projects of Department of Education of Guangdong Province (Grant No. 2016KTSCX034), and the Guangdong Science and Technology Plan (Grant No. 2017B010123002).

Conflicts of Interest: The authors declare no conflict of interest. The funders had no role in the design of the study; in the collection, analyses, or interpretation of data; in the writing of the manuscript, and in the decision to publish the results.

\section{References}

1. Yang, X.; Zhou, G.; Wong, W.-Y. Functionalization of Phosphorescent Emitters and Their Host Materials by Main-Group Elements for Phosphorescent Organic Light-Emitting Devices. Chem. Soc. Rev. 2015, 44, 8484-8575. [CrossRef] [PubMed]

2. Tyan, Y.S. Organic Light-Emitting-Diode Lighting Overview. J. Photonics Energy 2011, 1. [CrossRef]

3. Liu, B.; Gao, D.; Wang, J.; Wang, X.; Wang, L.; Zou, J.; Ning, H.; Peng, J. Progress of White Organic Light-Emitting Diodes. Acta Phys.-Chim. Sin. 2015, 31, 1823-1852.

4. Yang, X.; Zhou, G.; Wong, W.-Y. Recent Design Tactics for High Performance White Polymer Light-Emitting Diodes. J. Mater. Chem. C 2014, 2, 1760-1778. [CrossRef]

5. Jou, J.-H.; Kumar, S.; Agrawal, A.; Li, T.-H.; Sahoo, S. Approaches for Fabricating High Efficiency Organic Light Emitting Diodes. J. Mater. Chem. C 2015, 3, 2974-3002. [CrossRef]

6. Tang, C.W.; VanSlyke, V.A. Organic Electroluminescent Diodes. Appl. Phys. Lett. 1987, 51, 913-915. [CrossRef]

7. Ma, Y.; Zhang, H.; Shen, J.; Che, C. Electroluminescence from triplet metal-ligand charge-transfer excited state of transition metal complexes. Synth. Met. 1998, 94, 245-248. [CrossRef]

8. Baldo, M.A.; O'brien, D.F.; You, Y.; Shoustikov, A.; Sibley, S.; Thompson, M.E.; Forrest, S.R. Highly Efficient Phosphorescent Emission from Organic Electroluminescent Devices. Nature 1998, 395, 151-154. [CrossRef]

9. Fan, C.; Yang, C. Yellow/orange emissive heavy-metal complexes asphosphors in monochromatic and white organic light-emitting devices. Chem. Soc. Rev. 2014, 43, 6439-6469. [CrossRef] [PubMed]

10. Seifert, R.; Moraes, I.R.D.; Scholz, S.; Gather, M.C.; Lüssem, B.; Leo, K. Chemical Degradation Mechanisms of Highly Efficient Blue Phosphorescent Emitters Used for Organic Light Emitting Diodes. Org. Electron. 2013, 14, 115-123. [CrossRef]

11. Liu, B.; Xu, M.; Tao, H.; Ying, L.; Zou, J.; Wu, H.; Peng, J. Highly Efficient Red Phosphorescent Organic Light-Emitting Diodes Based on Solution Processed Emissive Layer. J. Lumin. 2013, 142, 35-39. [CrossRef]

12. Xiang, C.; Koo, W.; So, F.; Sasabe, H.; Kido, J. A Systematic Study on Efficiency Enhancements in Phosphorescent Green, Red and Blue Microcavity Organic Light Emitting Devices. Light Sci. Appl. 2013, 2, e74. [CrossRef]

13. Rao, M.V.M.; Su, Y.K.; Huang, T.S.; Chen, Y.C. White Organic Light Emitting Devices Based on Multiple Emissive Nanolayers. Nano-Micro Lett. 2010, 2, 242-246.

14. Eslamian, M. Inorganic and Organic Solution-Processed Thin Film Devices. Nano-Micro Lett. $2017,9$. [CrossRef]

15. Uoyama, H.; Goushi, K.; Shizu, K.; Nomura, H.; Adachi, C. Highly Efficient Organic Light-Emitting Diodes From Delayed Fluorescence. Nature 2012, 492, 234-238. [CrossRef] [PubMed]

16. Nishimoto, T.; Yasuda, T.; Lee, S.Y.; Kondo, R.; Adachi, C. A Six-carbazole-decorated Cyclophosphazene as A Host with High Triplet Energy to Realize Efficient Delayed-Fluorescence OLEDs. Mater. Horiz. 2014, 1, 264-269. [CrossRef] 
17. Zhang, Q.; Tsang, D.; Kuwabara, H.; Hatae, Y.; Li, B.; Takahashi, T.; Lee, S.Y.; Yasuda, T.; Adachi, C. Nearly 100\% Internal Quantum Efficiency in Undoped Electroluminescent Devices Employing Pure Organic Emitters. Adv. Mater. 2015, 27, 2096-2100. [CrossRef] [PubMed]

18. Zhang, Q.S.; Li, B.; Huang, S.P.; Nomura, H.; Tanaka, H.; Adachi, C. Efficient blue organic light-emitting diodes employing thermally activated delayed fluorescence. Nat. Photonics 2014, 8, 326-332. [CrossRef]

19. Wang, H.; Meng, L.Q.; Shen, X.X.; Wei, X.F.; Zheng, X.L.; Lv, X.P.; Yi, Y.P.; Wang, Y.; Wang, P.F. Light-Emitting Diodes: Highly Efficient Orange and Red Phosphorescent Organic Light-Emitting Diodes with Low Roll-Off of Efficiency using a Novel Thermally Activated Delayed Fluorescence Material as Host. Adv. Mater. 2015, 27, 4041-4047. [CrossRef] [PubMed]

20. Kim, B.S.; Lee, J.Y. Engineering of Mixed Host for High External Quantum Efficiency above $25 \%$ in Green Thermally Activated Delayed Fluorescence Device. Adv. Funct. Mater. 2015, 24, 3970-3977. [CrossRef]

21. Burroughes, J.H.; Bradley, D.D.C.; Brown, A.R.; Marks, R.N.; Mackay, K.; Friend, R.H.; Burns, P.L.; Homes, A.B. Light-Emitting Diodes Based on Conjugated Polymers. Nature 1990, 347, 539-541. [CrossRef]

22. Ying, L.; Ho, C.L.; Wu, H.; Cao, Y.; Wong, W.Y. White Polymer Light-Emitting Devices for Solid-State Lighting: Materials, Devices, and Recent Progress. Adv. Mater. 2014, 26, 2459-2473. [CrossRef] [PubMed]

23. Zou, J.; Wu, H.; Lam, C.S.; Wang, C.; Zhong, C.; Hu, S.; Ho, C.L.; Zhou, G.J.; Wu, H.; Choy, W.C.; et al. Simultaneous Optimization of Charge-Carrier Balance and Luminous Efficacy in Highly Efficient White Polymer Light-Emitting Devices. Adv. Mater. 2011, 23, 2976-2980. [CrossRef] [PubMed]

24. Niu, Y.H.; Liu, M.; Ka, J.W.; Bardeker, J.; Zin, M.; Schofield, Y.; Chi, Y.; Jen, A.K.-Y. Crosslinkable Hole-Transport Layer on Conducting Polymer for High-Efficiency White Polymer Light-Emitting Diodes. Adv. Mater. 2010, 9, 300-304. [CrossRef]

25. Sun, Q.J.; Wang, Y.A.; Li, L.S.; Wang, D.; Zhu, T.; Xu, J.; Yang, C.; Li, Y. Bright, Multicoloured Light-emitting Diodes Based on Quantum Dots. Nat. Photonics 2007, 1, 717-722. [CrossRef]

26. Dai, X.L.; Zhang, Z.X.; Jin, Y.Z.; Niu, Y.; Cao, H.J.; Liang, X.Y.; Chen, L.W.; Wang, J.P.; Peng, X.G. Solution-Processed, High Performance Light-Emitting Diodes Based on Quantum Dots. Nature 2014, 515, 96-100. [CrossRef] [PubMed]

27. Jiang, C.; Zhong, Z.; Liu, B.; He, Z.; Zou, J.; Wang, L.; Wang, J.; Peng, J.B.; Cao, Y. Coffee-Ring-Free Quantum Dot Thin Film Using Inkjet Printing from a Mixed-Solvent System on Modified ZnO Transport Layer for Light-Emitting Devices. ACS Appl. Mater. Interfaces 2016, 8, 26162-26168. [CrossRef] [PubMed]

28. Jiang, C.; Liu, H.; Liu, B.; Zhong, Z.; Zou, J.; Wang, J.; Wang, L.; Peng, J.; Cao, Y. Improved performance of inverted quantum dots light emitting devices by introducing double hole transport layers. Org. Electron. 2016, 31, 82-89. [CrossRef]

29. Shirasaki, Y.; Supran, G.J.; Bawendi, M.G.; Bulović, V. Emergence of colloidal quantum-dot light-emitting technologies. Nat. Photonics 2013, 7, 13-23. [CrossRef]

30. Chen, Z.; Nadal, B.; Mahler, B.; Aubin, H.; Dubertret, B. Quasi-2D Colloidal Semiconductor Nanoplatelets for Narrow Electroluminescence. Adv. Funct. Mater. 2014, 24, 295-302. [CrossRef]

31. Fan, F.; Kanjanaboos, P.; Saravanapavanantham, M.; Beauregard, E.; Ingram, G.; Yassitepe, E.; Adachi, M.M.; Voznyy, O.; Johnston, A.K.; Walters, G.; et al. Colloidal CdSe1-X SXNanoplatelets with Narrow and Continuously-Tunable Electroluminescence. Nano Lett. 2015, 15, 4611-4615. [CrossRef] [PubMed]

32. Liu, B.; Delikanli, S.; Gao, Y.; Gungor, K.; Demir, H.V. Nanocrystal light-emitting diodes based on type II nanoplatelets. Nano Energy 2018, 47, 115-122. [CrossRef]

33. Tan, Z.K.; Moghaddam, R.S.; Lai, M.L.; Docampo, P.; Higler, R.; Deschler, F.; Price, M.; Sadhanala, A.; Pazos, L.M.; Credgington, D.; et al. Bright light-emitting diodes based on organometal halide perovskite. Nat. Nanotechnol. 2014, 9, 687-692. [CrossRef] [PubMed]

34. Ji, H.; Shi, Z.; Sun, X.; Li, Y.; Li, S.; Lei, L.; Wu, D.; Xu, T.; Li, X.; Du, G. Vapor-Assisted Solution Approach for High-Quality Perovskite CH3NH3PbBr3 Thin Films for High-Performance Green Light-Emitting Diode Applications. ACS Appl. Mater. Interfaces 2017, 9, 42893-42904. [CrossRef] [PubMed]

35. Song, J.; Li, J.; Li, X.; Xu, L.; Dong, Y.; Zeng, H. Quantum dot light-emitting diodes based on inorganic perovskite cesium lead halides (CsPbX3). Adv. Mater. 2015, 27, 7162-7167. [CrossRef] [PubMed]

36. Zhang, X.; Wang, W.; Xu, B.; Liu, S.; Dai, H.; Bian, D.; Chen, S.; Wang, K.; Sun, X.W. Thin film perovskite light-emitting diode based on $\mathrm{CsPbBr} 3$ powders and interfacial engineering. Nano Energy 2017, 37, 40-45. [CrossRef] 
37. Liu, B.; Wang, L.; Gu, H.; Sun, H.; Demir, H.V. Highly Efficient Green Light-Emitting Diodes from All-Inorganic Perovskite Nanocrystals Enabled by a New Electron Transport Layer. Adv. Opt. Mater. 2018, 5, 1800220. [CrossRef]

38. Wang, L.; Liu, B.; Zhao, X.; Demir, H.V.; Gu, H.; Sun, H. Solvent-Assisted Surface Engineering for High Performance All-Inorganic Perovskite Nanocrystals Light-Emitting Diodes. ACS Appl. Mater. Interfaces 2018, 10, 19828-19835. [CrossRef] [PubMed]

39. Sasabe, H.; Kido, J. Development of High Performance OLEDs for General Lighting. J. Mater. Chem. C 2013, 1, 1699-1707. [CrossRef]

40. Wang, Q.; Ma, D. Management of Charges and Excitons for High-performance White Organic Light-emitting Diodes. Chem. Soc. Rev. 2010, 39, 2387-2398. [CrossRef] [PubMed]

41. Kim, D.Y.; Park, J.H.; Lee, J.W.; Hwang, S.; Oh, S.J.; Kim, J.; Sone, C.; Schubert, E.F.; Kim, J.K. Overcoming the fundamental light-extraction efficiency limitations of deep ultraviolet light-emitting diodes by utilizing transverse-magnetic-dominant emission. Light Sci. Appl. 2015, 4, e263. [CrossRef]

42. Kido, J.; Hongawa, K.; Okuyama, K.; Nagai, K. White Light-Emitting Organic Electroluminescent Devices Using The Poly (N-vinylcarbazole) Emitter Layer Doped with Three Fluorescent Dyes. Appl. Phys. Lett. 1994, 64, 815-817. [CrossRef]

43. Kido, J.; Kimura, M.; Nagai, K. Multilayer White Light-Emitting Organic Electroluminescent Device. Science 1995, 267, 1332-1334. [CrossRef] [PubMed]

44. Ou, Q.D.; Zhou, L.; Li, Y.Q.; Chen, S.; Chen, J.D.; Li, C.; Wang, Q.K.; Lee, S.T.; Tang, J.X. Light-Emitting Diodes: Extremely Efficient White Organic Light-Emitting Diodes for General Lighting. Adv. Funct. Mater. 2014, 24, 7249. [CrossRef]

45. Duan, L.; Zhang, D.Q.; Wu, K.W.; Huang, X.Q.; Wang, L.D.; Qiu, Y. Controlling the Recombination Zone of White Organic Light-Emitting Diodes with Extremely Long Lifetimes. Adv. Funct. Mater. 2011, 21, 3540-3545. [CrossRef]

46. Luo, D.X.; Yang, Y.B.; Huang, L.; Liu, B.; Zhao, Y. High-performance hybrid white organic light-emitting diodes exploiting blue thermally activated delayed fluorescent dyes. Dyes Pigments 2017, 147, 83-89. [CrossRef]

47. Sun, N.; Zhao, Y.B.; Zhao, F.C.; Chen, Y.H.; Yang, D.Z.; Chen, J.S.; Ma, D.G. A white organic light-emitting diode with ultra-high color rendering index, high efficiency, and extremely low efficiency roll-off. Appl. Phys. Lett. 2014, 105, 013303. [CrossRef]

48. Jou, J.-H.; Wu, R.-Z.; Yu, H.-H.; Li, C.-J.; Jou, Y.-C.; Peng, S.-H.; Chen, Y.-L.; Chen, C.-T.; Shen, S.-M.; Joers, P.; et al. Artificial Dusk-Light Based on Organic Light Emitting Diodes. ACS Photonics 2014, 1, $27-31$. [CrossRef]

49. Liu, B.; Xu, M.; Wang, L.; Tao, H.; Su, Y.; Gao, D.; Lan, L.; Zou, J.; Peng, J. Very-High Color Rendering Index Hybrid White Organic Light-Emitting Diodes with Double Emitting Nanolayers. Nano-Micro Lett. 2014, 6, 335-339. [CrossRef]

50. Liu, B.; Luo, D.; Gao, D.; Wang, X.; Xu, M.; Zou, J.; Ning, H.; Wang, L.; Peng, J.; Cao, Y. An ideal host-guest system to accomplish high-performance greenishyellow and hybrid white organic light-emitting diodes. Org. Electron. 2015, 27, 29-34. [CrossRef]

51. Jou, J.H.; Wu, M.H.; Shen, S.M.; Wang, H.C.; Chen, S.Z.; Chen, S.H.; Lin, C.R.; Hsieh, Y.L. Sunlight-Style Color-Temperature Tunable Organic Light-Emitting Diode. Appl. Phys. Lett. 2009, 95, 013307. [CrossRef]

52. Jou, J.-H.; Hsieh, C.-Y.; Tseng, J.-R.; Peng, S.-H.; Jou, Y.-C.; Hong, J.H.; Shen, S.-M.; Tang, M.-C.; Chen, P.-C.; Lin, C.-H. Candle Light-Style Organic Light-Emitting Diodes. Adv. Funct. Mater. 2013, 23, $2750-2757$. [CrossRef]

53. Liu, B.; Nie, H.; Zhou, X.B.; Hu, S.B.; Luo, D.X.; Gao, D.Y.; Zou, J.H.; Xu, M.; Wang, L.; Zhao, Z.J.; et al. Manipulation of Charge and Exciton Distribution Based on Blue Aggregation-Induced Emission Fluorophors: A Novel Concept to Achieve High-Performance Hybrid White Organic Light-Emitting Diodes. Adv. Funct. Mater. 2016, 26, 776-783. [CrossRef]

54. Liu, B.; Nie, H.; Lin, G.; Hu, S.; Gao, D.; Zou, J.; Xu, M.; Wang, L.; Zhao, Z.; Ning, H.; et al. High-Performance Doping-Free Hybrid White OLEDs Based on Blue Aggregation-Induced Emission Luminogens. ACS Appl. Mater. Interfaces 2017, 9, 34162-34171. [CrossRef] [PubMed] 
55. Liu, B.; Wang, L.; Gao, D.Y.; Xu, M.; Zhu, X.H.; Zou, J.H.; Lan, L.F.; Ning, H.L.; Peng, J.B.; Cao, Y. Harnessing charge and exciton distribution towards extremely high performance: The critical role of guests in single-emitting-layer white OLEDs. Mater. Horiz. 2015, 2, 536-544. [CrossRef]

56. Zhang, L.; Li, X.-L.; Luo, D.; Xiao, P.; Xiao, W.; Song, Y.; Ang, Q.; Liu, B. Strategies to Achieve High-Performance White Organic Light-Emitting Diodes. Materials 2017, 10, 1378. [CrossRef] [PubMed]

57. Chen, J.; Zhao, F.; Ma, D. Hybrid White OLEDs with Fluorophors and Phosphors. Mater. Today 2014, 17, 175-183. [CrossRef]

58. Xiao, P.; Dong, T.; Xie, J.; Luo, D.; Yuan, J.; Liu, B. Emergence of White Organic Light-Emitting Diodes Based on Thermally Activated Delayed Fluorescence. Appl. Sci. 2018, 8, 299. [CrossRef]

59. Schwartz, G.; Reineke, S.; Rosenow, T.C.; Walzer, K.; Leo, K. Triplet Harvesting in Hybrid White Organic Light-Emitting Diodes. Adv. Funct. Mater. 2009, 19, 1319-1333. [CrossRef]

60. Zhang, D.D.; Duan, L.; Zhang, Y.G.; Cai, M.H.; Zhang, D.Q.; Qiu, Y. Highly efficient hybrid warm white organic light-emitting diodes using a blue thermally activated delayed fluorescence emitter: Exploiting the external heavy-atom effect. Light Sci. Appl. 2015, 4, e232. [CrossRef]

61. Zhang, D.D.; Duan, L.; Li, Y.L.; Zhang, D.Q.; Qiu, Y. Highly efficient and color-stable hybrid warm white organic light-emitting diodes using a blue material with thermally activated delayed fluorescence. J. Mater. Chem. C 2014, 2, 8191-8197. [CrossRef]

62. Zhang, D.D.; Zhang, D.Q.; Duan, L. Exploiting p-Type Delayed Fluorescence in Hybrid White OLEDs: Breaking the Trade-off between High Device Efficiency and Long Lifetime. ACS Appl. Mater. Interfaces 2016, 8, 23197-23203. [CrossRef] [PubMed]

63. Chen, Y.; Zhao, F.; Zhao, Y.; Chen, J.; Ma, D. Ultra-simple hybrid white organic light-emitting diodes with high efficiency and CRI trade-off: Fabrication and emission-mechanism analysis. Org. Electron. 2012, 13, 2807-2815. [CrossRef]

64. Schwartz, G.; Fehse, K.; Pfeiffer, M.; Walzer, K.; Leo, K. Highly efficient white organic light emitting diodes comprising an interlayer to separate fluorescent and phosphorescent regions. Appl. Phys. Lett. 2006, 89, 083509. [CrossRef]

65. Zhao, Y.; Zhu, L.; Chen, J.; Ma, D. Improving Color Stability of Blue/Orange Complementary White OLEDs by Using Single-Host Double-Emissive Layer Structure: Comprehensive Experimental Investigation into the Device Working Mechanism. Org. Electron. 2012, 13, 1340-1348. [CrossRef]

66. Luo, D.X.; Yang, Y.F.; Xiao, Y.; Zhao, Y.; Yang, Y.B.; Liu, B.Q. Regulating Charge and Exciton Distribution in High-Performance Hybrid White Organic Light-Emitting Diodes with n-Type Interlayer Switch. Nano-Micro Lett. 2017, 9. [CrossRef]

67. Liu, B.; Xu, M.; Wang, L.; Su, Y.J.; Gao, D.Y.; Tao, H.; Lan, L.F.; Zou, J.H.; Peng, J.B. High-Performance Hybrid White Organic Light-Emitting Diodes Comprising Ultrathin Blue and Orange Emissive Layers. Appl. Phys. Express 2013, 6, 122101. [CrossRef]

68. Sun, N.; Wang, Q.; Zhao, Y.B.; Yang, D.Z.; Zhao, F.C.; Chen, J.S.; Ma, D.G. A hybrid white organic light-emitting diode with above $20 \%$ external quantum efficiency and extremely low efficiency roll-off. J. Mater. Chem. C 2014, 2, 7494-7504. [CrossRef]

69. Poloek, A.; Chen, C.-T.; Chen, C.-T. High performance hybrid white and multi-colour electroluminescence from a new host material for a heteroleptic naphthyridinolate platinum complex dopant. J. Mater. Chem. C 2014, 2, 1376-1380. [CrossRef]

70. Liu, B.; Xu, M.; Wang, L.; Tao, H.; Su, Y.J.; Gao, D.Y.; Lan, L.F.; Zou, J.H.; Peng, J.B. Simplified hybrid white organic light-emitting diodes with efficiency/efficiency roll-off/color rendering index/color-stability trade-off. Phys. Status Solidi RRL 2014, 8, 719-723. [CrossRef]

71. Liu, B.; Luo, D.X.; Zou, J.H.; Gao, D.Y.; Ning, H.L.; Wang, L.; Peng, J.B.; Cao, Y. A host-guest system comprising high guest concentration to achieve simplified and high-performance hybrid white organic light-emitting diodes. J. Mater. Chem. C 2015, 3, 6359-6366. [CrossRef]

72. Sun, Y.R.; Giebink, N.C.; Kanno, H.; Ma, B.W.; Thompson, M.E.; Forrest, S.R. Management of Singlet and Triplet Excitons for Efficient White Organic Light-Emitting Devices. Nature 2006, 440, 908-912. [CrossRef] [PubMed]

73. Chen, P.; Xie, W.F.; Li, K.; Guan, T.; Duan, Y.; Zhao, Y.; Liu, S.Y.; Ma, C.S.; Zhang, L.Y.; Li, B. White organic light-emitting devices with a bipolar transport layer between blue fluorescent and orange phosphorescent emitting layers. Appl. Phys. Lett. 2007, 91, 023505. [CrossRef] 
74. Liu, B.; Zou, J.H.; Zhou, Z.W.; Wang, L.; Xu, M.; Tao, H.; Gao, D.Y.; Lan, L.Y.; Ning, H.L.; Peng, J.B. Efficient single-emitting layer hybrid white organic light-emitting diodes with low efficiency roll-off, stable color and extremely high luminance. J. Ind. Eng. Chem. 2015, 30, 85-91. [CrossRef]

75. Liu, B.; Xu, M.; Tao, H.; Su, Y.J.; Gao, D.Y.; Zou, J.H.; Lan, L.F.; Peng, J.B. The effect of spacer in hybrid white organic light emitting diodes. Chin. Sci. Bull. 2014, 59, 3090-3097. [CrossRef]

76. Schwartz, G.; Pfeiffer, M.; Reineke, S.; Walzer, K.; Leo, K. Harvesting Triplet Excitons from Fluorescent Blue Emitters in White Organic Light-Emitting Diodes. Adv. Mater. 2007, 19, 3672-3676. [CrossRef]

77. Ye, J.; Zheng, C.-J.; Ou, X.-M.; Zhang, X.-H.; Fung, M.-K.; Lee, C.-S. Management of Singlet and Triplet Excitons in a Single Emission Layer: A Simple Approach for a High-Efficiency Fluorescence/Phosphorescence Hybrid White Organic Light-Emitting Device. Adv. Mater. 2012, 24, 3410-3414. [CrossRef] [PubMed]

78. Liu, B.; Xu, M.; Wang, L.; Zou, J.H.; Tao, H.; Su, Y.J.; Gao, D.Y.; Ning, H.L.; Lan, L.F.; Peng, J.B. Regulating charges and excitons in simplified hybrid white organic light-emitting diodes: The key role of concentration in single dopant host-guest systems. Org. Electron. 2014, 15, 2616-2623. [CrossRef]

79. Li, X.L.; Ouyang, X.H.; Liu, M.; Ge, Z.Y.; Peng, J.B.; Cao, Y.; Su, S.J. Highly efficient single-and multi-emission-layer fluorescent/phosphorescent hybrid white organic light-emitting diodes with $\sim 20 \%$ external quantum efficiency. J. Mater. Chem. C 2015, 3, 9233-9239. [CrossRef]

80. Ouyang, X.H.; Li, X.L.; Bai, Y.Q.; Mi, D.B.; Ge, Z.Y.; Su, S.J. Highly-efficient hybrid white organic light-emitting diodes based on a high radiative exciton ratio deepblue emitter with improved concentration of phosphorescent dopant. RSC Adv. 2015, 5, 32298-32306. [CrossRef]

81. Su, S.-J.; Gonmori, E.; Sasabe, H.; Kido, J. Highly efficient organic blue- and white-light-emitting devices having a carrier- and exciton-confining structure for reduced efficiency roll-off. Adv. Mater. 2008, 20, 4189-4194. [CrossRef]

82. Huang, W.Y.; Chen, Z.W.; You, H.W.; Fan, F.C.; Chen, H.F.; Wong, K.T. Efficient carrier- and exciton-confining device structure that enhances blue PhOLED efficiency and reduces efficiency roll-off. Org. Electron. 2011, 12, 575-581. [CrossRef]

83. Zhou, J.; Zou, J.; Dai, C.; Zhang, Y.; Luo, X.; Liu, B. High-Efficiency and High-Luminance Three-Color White Organic Light-Emitting Diodes with Low Efficiency Roll-Off. ECS J. Solid State Sci. Technol. 2018, 7, R99-R103. [CrossRef]

84. Reineke, S.; Lindner, F.; Schwartz, G.; Seidler, N.; Walzer, K.; Lüssem, B.; Leo, K. White organic light-emitting diodes with fluorescent tube efficiency. Nature 2009, 459, 234-238. [CrossRef] [PubMed]

85. Lee, J.; Chopra, N.; Bera, D.; Maslov, S.; Eom, S.H.; Zheng, Y.; Holloway, P.; Xue, J.; So, F. DOWN-CONVERSION WHITE OLEDS: Down-Conversion White Organic Light-Emitting Diodes Using Microcavity Structure. Adv. Eng. Mater. 2011, 1, 174-178. [CrossRef]

86. Liu, B.; Tao, H.; Wang, L.; Gao, D.Y.; Liu, W.C.; Zou, J.H.; Xu, M.; Ning, H.L.; Peng, J.B.; Cao, Y. High-performance doping-free hybrid white organic light-emitting diodes: The exploitation of ultrathin emitting nanolayers (<1 nm). Nano Energy 2016, 26, 26-36. [CrossRef]

87. Zhao, Y.B.; Chen, J.S.; Ma, D.G. Ultrathin Nondoped Emissive Layers for Efficient and Simple Monochrome and White Organic Light-Emitting Diodes. ACS Appl. Mater. Interfaces 2013, 5, 965-971. [CrossRef] [PubMed]

88. Xue, K.W.; Han, G.G.; Duan, Y.; Chen, P.; Yang, Y.Q.; Yang, D.; Duan, Y.H.; Wang, X.; Zhao, Y. Doping-free orange and white phosphorescent organic light-emitting diodes with ultra-simply structure and excellent color stability. Org. Electron. 2015, 18, 84-88. [CrossRef]

89. Xue, K.W.; Sheng, R.; Duan, Y.; Chen, P.; Chen, B.Y.; Wang, X.; Duan, Y.H.; Zhao, Y. Efficient non-doped monochrome and white phosphorescent organic light-emitting diodes based on ultrathin emissive layers. Org. Electron. 2015, 26, 451-457. [CrossRef]

90. Yin, Y.M.; Yu, J.; Cao, H.T.; Zhang, L.T.; Sun, H.Z.; Xie, W.F. Efficient non-doped phosphorescent orange, blue and white organic light-emitting devices. Sci. Rep. 2014, 4, 6754. [CrossRef] [PubMed]

91. Guo, F.; Ma, D. White organic light-emitting diodes based on tandem structures. Appl. Phys. Lett. 2005, 87, 173510. [CrossRef]

92. Yook, K.S.; Jeon, S.O.; Min, S.Y.; Lee, J.Y.; Yang, H.J.; Noh, T.; Kang, S.K.; Lee, T.W. Highly Efficient p-i-n and Tandem Organic Light-Emitting Devices Using an Air-Stable and Low-Temperature-Evaporable Metal Azide as an n-Dopant. Adv. Funct. Mater. 2010, 20, 1797-1802. [CrossRef] 
93. Sun, H.D.; Guo, Q.X.; Yang, D.Z.; Chen, Y.H.; Chen, J.S.; Ma, D.G. High Efficiency Tandem Organic Light Emitting Diode Using an Organic Heterojunction as the Charge Generation Layer: An Investigation into the Charge Generation Model and Device Performance. ACS Photonics 2015, 2, 271-279. [CrossRef]

94. Ding, L.; Sun, Y.Q.; Chen, H.; Zu, F.S.; Wang, Z.K.; Liao, L.S. A novel intermediate connector with improved charge generation and separation for large-area tandem white organic lighting devices. J. Mater. Chem. C 2014, 2, 10403-10408. [CrossRef]

95. Chang, C.C.; Chen, J.F.; Hwang, S.W.; Chen, C.H. Highly efficient white organic electroluminescent devices based on tandem architecture. Appl. Phys. Lett. 2005, 87. [CrossRef]

96. Fleetham, T.; Li, G.; Li, J. Phosphorescent Pt (II) and Pd (II) Complexes for Efficient, High-Color-Quality, and Stable OLEDs. Adv. Mater. 2017, 29, 1601861. [CrossRef] [PubMed]

97. Fleetham, T.; Huang, L.; Li, J. Tetradentate Platinum Complexes for Efficient and Stable Excimer-Based White OLEDs. Adv. Funct. Mater. 2015, 24, 6066-6073. [CrossRef]

98. Fleetham, T.; Li, G.; Wen, L.; Li, J. Efficient "Pure" Blue OLEDs Employing Tetradentate Pt Complexes with a Narrow Spectral Bandwidth. Adv. Mater. 2014, 26, 7116-7121. [CrossRef] [PubMed]

99. Sun, N.; Wang, Q.; Zhao, Y.B.; Chen, Y.H.; Yang, D.Z.; Zhao, F.C.; Chen, J.S.; Ma, D.G. High-Performance Hybrid White Organic Light-Emitting Devices without Interlayer between Fluorescent and Phosphorescent Emissive Regions. Adv. Mater. 2014, 26, 1617-1621. [CrossRef] [PubMed]

100. Du, X.; Tao, S.; Huang, Y.; Yang, X.; Ding, X.; Zhang, X. Efficient Fluorescence/Phosphorescence White Organic Light-Emitting Diodes with Ultra High Color Stability and Mild Efficiency Roll-Off. Appl. Phys. Lett. 2015, 107, 183304. [CrossRef]

101. Liu, B.; Wang, L.; Gao, D.Y.; Zou, J.H.; Ning, H.L.; Peng, J.B.; Cao, Y. Extremely high-efficiency and ultrasimplified hybrid white organic light-emitting diodes exploiting double multifunctional blue emitting layers. Light Sci. Appl. 2016, 5, e16137. [CrossRef]

102. Berggren, M.; Gustafsson, G.; Inganäs, O.; Andersson, M.R.; Hjertberg, T.; Wennerström, O. White Light from an Electroluminescent Diode Made from Poly[3(4-Octylphenyl)-2,2'-Bithiophene] and an Oxadiazole Derivative. J. Appl. Phys. 1994, 76, 7530-7534. [CrossRef]

103. Feng, J.; Li, F.; Gao, W.; Liu, S.; Wang, Y. White Light Emission from Exciplex Using Tris-(8-Hydroxyquinoline)Aluminum as Chromaticity-Tuning Layer. Appl. Phys. Lett. 2001, 78, 3947-3949. [CrossRef]

104. Gebler, D.D.; Wang, Y.Z.; Blatchford, J.W.; Jessen, S.W. Exciplex Emission in Bilayer Polymer Light-Emitting Devices. Appl. Phys. Lett. 1997, 70, 1644-1646. [CrossRef]

105. Chao, C.I.; Chen, S.A. White Light Emission from Exciplex in a Bilayer Device with Two Blue Light-Emitting Polymers. Appl. Phys. Lett. 1998, 73, 426-428. [CrossRef]

106. Chapran, M.; Angioni, E.; Findlay, N.J.; Breig, B.; Cherpak, V.; Stakhira, P.; Tuttle, T.; Volyniuk, D.; Grazulevicius, J.V.; Nastishin, Y.A.; et al. An ambipolar BODIPY derivative for a white exciplex OLED and cholesteric liquid crystal laser towards multi-functional devices. ACS Appl. Mater. Interfaces 2017, 9, 4750-4757. [CrossRef] [PubMed]

107. Cekaviciute, M.; Simokaitiene, J.; Volyniuk, D.; Sini, G.; Grazulevicius, J.V. Arylfluorenyl-substituted metoxytriphenylamines as deep blue exciplex forming bipolar semiconductors for white and blue organic light emitting diodes. Dyes Pigments 2017, 140, 187-202. [CrossRef]

108. Cherpak, V.; Stakhira, P.; Minaev, B.; Baryshnikov, G.; Stromylo, E.; Helzhynskyy, I.; Chapran, M.; Volyniuk, D.; Hotra, Z.; Dabuliene, A.; et al. Mixing of Phosphorescent and Exciplex Emission in Efficient Organic Electroluminescent Devices. ACS Appl. Mater. Interfaces 2015, 7, 1219-1225. [CrossRef] [PubMed]

109. Chen, Z.; Liu, X.K.; Zheng, C.J.; Ye, J.; Liu, C.L.; Li, F.; Ou, X.M.; Lee, C.S.; Zhang, X.H. High Performance Exciplex-Based Fluorescence-Phosphorescence White Organic Light-Emitting Device with Highly Simplified Structure. Chem. Mater. 2015, 27, 5206-5211. [CrossRef]

110. Luo, D.X.; Xiao, Y.; Hao, M.M.; Zhao, Y.; Yang, Y.B.; Gao, Y.; Liu, B. Doping-free white organic light-emitting diodes without blue molecular emitter: An unexplored approach to achieve high performance via exciplex emission. Appl. Phys. Lett. 2017, 110, 061105. [CrossRef]

111. Goushi, K.; Yoshida, K.; Sato, K.; Adachi, C. Organic light-emitting diodes employing efficient reverse intersystem crossing for triplet-to-singlet state conversion. Nat. Photonics 2012, 6, 253-258. [CrossRef] 
112. Wu, S.F.; Li, S.H.; Wang, Y.K.; Huang, C.C.; Sun, Q.; Liang, J.J.; Liao, L.S.; Fung, M.-K. White Organic LED with a Luminous Efficacy Exceeding $100 \mathrm{~lm} \mathrm{w}-1$ without Light Out-Coupling Enhancement Techniques. Adv. Funct. Mater. 2017, 27, 1701314. [CrossRef]

113. Cocchi, M.; Virgili, D.; Giro, G.; Fattori, V. Efficient Exciplex Emitting Organic Electroluminescent Devices. Appl. Phys. Lett. 2002, 80, 2401-2403. [CrossRef]

114. Lee, S.; Kim, K.-H.; Limbach, D.; Park, Y.-S.; Kim, J.-J. Low Roll-Off and High Efficiency Orange Organic Light Emitting Diodes with Controlled Co-Doping of Green and Red Phosphorescent Dopants in an Exciplex Forming Co-Host. Adv. Funct. Mater. 2013, 23, 4105-4110. [CrossRef]

115. Chen, D.; Xie, G.; Cai, X.; Liu, M.; Cao, Y.; Su, S.-J. Fluorescent Organic Planar pn Heterojunction Light-Emitting Diodes with Simplified Structure, Extremely Low Driving Voltage, and High Efficiency. Adv. Mater. 2016, 28, 239-244. [CrossRef] [PubMed]

116. Chen, D.; Wang, Z.; Wang, D.; Wu, Y.-C.; Lo, C.-C.; Lien, A.; Cao, Y.; Su, S.-J. Efficient Exciplex Organic Light-Emitting Diodes with A Bipolar Acceptor. Org. Electron. 2015, 25, 79-84. [CrossRef]

117. Jiang, X.; Register, R.A.; Killeen, K.A.; Thompson, M.E.; Pschenitzka, T.; Hebner, T.R.; Sturm, J.C. Effect of Carbazole-oxadiazole Excited-State Complexes on the Efficiency of Dye-Doped Light-Emitting Diodes. J. Appl. Phys. 2002, 91, 6717-6724. [CrossRef]

118. Pikna, P.; Skoromets, V.; Becker, C.; Fejfar, A.; Kužel, P. Thin Film Polycrystalline Si Solar Cells Studied in Transient Regime by Optical Pump-Terahertz Probe Spectroscopy. Appl. Phys. Lett. 2015, 107. [CrossRef]

119. Zhang, M.; Chen, Z.; Xiao, L.; Qu, B.; Gong, Q. High-Color-Quality White Top-Emitting Organic Electroluminescent Devices Based on Both Exciton and Electroplex Emission. Appl. Phys. Express 2013, 4, 784-788. [CrossRef]

120. Lee, H.W.; Kim, H.J.; Kim, Y.S.; Kim, J.; Song, E.L.; Lee, H.W.; Kim, Y.K.; Yoon, S.S. Emitting Materials based on Phenylanthracene-Substituted Naphthalene Derivatives for Organic Light-Emitting Diodes. J. Luminescence 2015, 165, 99-104. [CrossRef]

121. Chen, D.; Liu, K.; Gan, L.; Liu, M.; Gao, K.; Xie, G.; Ma, Y.; Cao, Y.; Su, S.-J. Modulation of Exciton Generation in Organic Active Planar pn Heterojunction: Toward Low Driving Voltage and High-Efficiency OLEDs Employing Conventional and Thermally Activated Delayed Fluorescent Emitters. Adv. Mater. 2016, 28, 6758-6765. [CrossRef] [PubMed]

122. Cheng, J.A.; Chen, C.H. White Organic Electroluminescence from an Exciplex Based on the Novel Substituted Aluminium Quinolate Complex. J. Mater. Chem. 2005, 15, 1179-1185. [CrossRef]

123. Kalinowski, J.; Cocchi, M.; Virgili, D.; Fattori, V.; Williams, J. Mixing of Excimer and Exciplex Emission: A New Way to Improve White Light Emitting Organic Electrophosphorescent Diodes. Adv. Mater. 2010, 19, 4000-4005. [CrossRef]

124. Brovelli, S.; Sforazzini, G.; Serri, M.; Winroth, G.; Suzuk, K.; Meinardi, F.; Anderson, H.L.; Cacialli, F. Emission Color Trajectory and White Electroluminescence Through Supramolecular Control of Energy Transfer and Exciplex Formation in Binary Blends of Conjugated Polyrotaxanes. Adv. Funct. Mater. 2012, 22, 4284-4291. [CrossRef]

125. Goushi, K.; Adachi, C. Efficient Organic Light-Emitting Diodes Through Up-Conversion from Triplet to Singlet Excited States of Exciplexes. Appl. Phys. Lett. 2012, 101, 3174-3187. [CrossRef]

126. Jankus, V.; Chiang, C.J.; Dias, F.; Monkman, A.P. Deep Blue Exciplex Organic Light-Emitting Diodes with Enhanced Efficiency; P-type or E-type Triplet Conversion to Singlet Excitons. Adv. Mater. 2013, 25, 1455-1459. [CrossRef] [PubMed]

127. He, S.J.; Wang, D.K.; Jiang, N.; Tse, J.S.; Lu, Z.H. Tunable Excitonic Processes at Organic Heterojunctions. Adv. Mater. 2016, 28, 649-654. [CrossRef] [PubMed]

128. Baldo, M.A.; O’Brien, D.F.; Thompson, M.E.; Forrest, S.R. Excitonic Singlet-Triplet Ratio in a Semiconducting Organic Thin Film. Phys. Rev. B 1999, 60, 14422-14428. [CrossRef]

129. Adachi, C.; Baldo, M.A.; Thompson, M.E.; Forrest, S.R. Nearly 100\% Internal Phosphorescence Efficiency in an Organic Light-Emitting Device. J. Appl. Phys. 2001, 90, 5048-5051. [CrossRef]

130. Nozoe, S.; Matsuda, M. Enhanced emission by accumulated charges at organic/metal interfaces generated during the reverse bias of organic light emitting diodes. Appl. Sci. 2017, 7, 1045. [CrossRef]

131. Sang, K.; Kang, L.; Lee, J.E.; Yoo, J.; Yi, Y.; Kwon, H.; Lee, H.; Park, M.H.; Chung, Y. Synthesis and electroluminescence properties of 3-(trifluoromethyl)phenyl-substituted 9,10-diarylanthracene derivatives for blue organic light-emitting diodes. Appl. Sci. 2017, 7, 1109. [CrossRef] 
132. Gao, C.Y.; Chen, K.L.; Sze, P.W.; Chen, Y.C.; Huang, C.J. Enhancement and Reduction of Nonradiative Decay Process in Organic Light-Emitting Diodes by Gold Nanoparticles. Appl. Sci. 2016, 6, 441. [CrossRef]

133. Liu, B.; Xu, M.; Wang, L.; Tao, H.; Su, Y.; Gao, D.; Zou, J.; Lan, L.; Peng, J. Comprehensive Study on the Electron Transport Layer in Blue Flourescent Organic Light-Emitting Diodes. ECS J. Solid State Sci. Technol. 2015, 2, R258-R261. [CrossRef]

134. Rajamalli, P.; Senthilkumar, N.; Gandeepan, P.; Huang, P.-Y.; Huang, M.-J.; Yang, C.-Y.; Chiu, M.-J.; Chu, L.-K.; Lin, H.-W.; Cheng, C.-H. A New Molecular Design Based on Thermally Activated Delayed Fluorescence for Highly Efficient Organic Light Emitting Diodes. J. Am. Chem. Soc. 2016, 138, 628-634. [CrossRef] [PubMed]

135. Kim, G.H.; Lampande, R.; Im, J.B.; Lee, J.M.; Lee, J.Y.; Kwon, J.H. Controlling the exciton lifetime of blue thermally activated delayed fluorescence emitters using a heteroatom-containing pyridoindole donor moiety. Mater. Horiz. 2017, 4, 619-624. [CrossRef]

136. Yang, Z.Y.; Mao, Z.; Xie, Z.L.; Zhang, Y.; Liu, S.W.; Zhao, J.; Xu, J.R.; Chi, Z.G.; Aldred, M.P. Recent advances in organic thermally activated delayed fluorescence materials. Chem. Soc. Rev. 2017, 46, 915-1016. [CrossRef] [PubMed]

137. Zhang, D.D.; Cai, M.H.; Zhang, Y.G.; Zhang, D.Q.; Duan, L. Sterically Shielded Blue Thermally Activated Delayed Fluorescence Emitters with Improved Efficiency and Stability. Mater. Horiz. 2016, 3, 145-151. [CrossRef]

138. Tao, Y.; Yuan, K.; Chen, T.; Xu, P.; Li, H.; Chen, R.; Zheng, C.; Zhang, L.; Huang, W. Thermally Activated Delayed Fluorescence Materials Towards the Breakthrough of Organoelectronics. Adv. Mater. 2014, 26, 7931-7958. [CrossRef] [PubMed]

139. Masui, K.; Nakanotani, H.; Adachi, C. Analysis of exciton annihilation in high efficiency sky-blue organic light-emitting diodes with thermally activated delayed fluorescence. Org. Electron. 2013, 14, 2721-2726. [CrossRef]

140. Zhang, D.; Duan, L.; Li, C.; Li, Y.; Li, H.; Zhang, D.; Qiu, Y. High-Efficiency Fluorescent Organic Light-Emitting Devices Using Sensitizing Hosts with a Small Singlet-Triplet Exchange Energy. Adv. Mater. 2014, 26, 5050-5055. [CrossRef] [PubMed]

141. Liu, X.; Chen, Z.; Zheng, C.; Liu, C.; Lee, C.; Li, F.; Ou, X.-M.; Zhang, X.-H. Prediction and Design of Efficient Exciplex Emitters for High-Efficiency, Thermally Activated Delayed-Fluorescence Organic Light-Emitting Diodes. Adv. Mater. 2015, 27, 2378-2383. [CrossRef] [PubMed]

142. Liu, X.; Chen, Z.; Zheng, C.-J.; Chen, M.; Liu, W.; Zhang, X.-H.; Lee, C.-S. Nearly 100\% Triplet Harvesting in Conventional Fluorescent Dopant-Based Organic Light-Emitting Devices Through Energy Transfer from Exciplex. Adv. Mater. 2015, 27, 2025-2030. [CrossRef] [PubMed]

143. Zhang, T.; Chu, B.; Li, W.; Su, Z.; Peng, Q.M.; Zhao, B.; Luo, Y.; Jin, F.; Yan, X.; Gao, Y.; et al. Efficient Triplet Application in Exciplex Delayed-Fluorescence OLEDs Using A Reverse Intersystem Crossing Mechanism Based on A $\triangle E S-T$ of Around Zero. ACS Appl. Mater. Interfaces 2014, 6, 11907-11914. [CrossRef] [PubMed]

144. Ban, X.; Sun, K.; Sun, Y.; Huang, B.; Jiang, W. Design of High Triplet Energy Electron Transporting Material for Exciplex-Type Host: Efficient Blue and White Phosphorescent OLEDs based on Solution Processing. Org. Electron. 2016, 33, 9-14. [CrossRef]

145. Dayal, G.; Xin, Y.C.; Soci, C.; Singh, R. High-Q Plasmonic Fano Resonance for Multiband Surface-Enhanced Infrared Absorption of Molecular Vibrational Sensing. Adv. Opt. Mater. 2016, 5, 1600559. [CrossRef]

146. Chen, S.; Qu, Q.; Kong, M.; Zhao, X.; Yu, Z.; Jia, P.; Huang, W. On the Origin of the Shift in Color in White Organic Light-Emitting Diodes. J. Mater. Chem. C 2013, 1, 3508-3524. [CrossRef]

147. Wang, Q.; Ding, J.; Ma, D.; Cheng, Y.; Wang, L.; Jing, X.; Wang, F. Harvesting Excitons Via Two Parallel Channels for Efficient White Organic LEDs with Nearly 100\% Internal Quantum Efficiency: Fabrication and Emission Mechanism Analysis. Adv. Funct. Mater. 2009, 19, 84-95. [CrossRef]

148. Son, Y.H.; Kim, Y.J.; Park, M.J.; Oh, H.Y.; Park, J.S.; Yang, J.H.; Suh, M.C.; Kwon, J.H. Small single-triplet energy gap bipolar host materials for phosphorescent blue and white organic light emitting diodes. J. Mater. Chem. C 2013, 1, 5008-5014. [CrossRef]

149. Zhao, B.; Zhang, T.Y.; Li, W.L.; Su, Z.S.; Chu, B.; Yan, X.W.; Jin, F.M.; Gao, Y.; Wu, H. Organic Electronics Highly efficient and color stable single-emitting-layer fluorescent WOLEDs with delayed fluorescent host. Org. Electron. 2015, 23, 208-212. [CrossRef] 
150. Liu, B.; Wang, L.; Xu, M.; Tao, H.; Gao, D.; Zou, J.; Lan, L.; Ning, H.; Peng, J.; Cao, Y. Extremely Stable-color Flexible White Organic Light-emitting Diodes with Efficiency Exceeding $100 \mathrm{~lm}$ W-1. J. Mater. Chem. C 2014, 2, 9836-9841. [CrossRef]

151. Liu, B.; Xu, M.; Wang, L.; Yan, X.; Tao, H.; Su, Y.; Gao, D.; Lan, L.; Zou, J.; Peng, J. Investigation and Optimization of Each Organic Layer: A Simple But Effective Approach Towards Achieving High-Efficiency Hybrid White Organic Light-Emitting Diodes. Org. Electron. 2014, 15, 926-936. [CrossRef]

152. Liu, B.; Wang, L.; Xu, M.; Tao, H.; Xia, X.; Zou, J.; Su, Y.; Gao, D.; Lan, L.; Peng, J. Simultaneous Achievement of Low Efficiency Roll-Off and Stable Color in Highly Efficient Single-Emitting-Layer Phosphorescent White Organic Light-Emitting Diodes. J. Mater. Chem. C 2014, 2, 5870-5877. [CrossRef]

153. Liu, B.; Xu, Z.P.; Zou, J.H.; Tao, H.; Xu, M.; Gao, D.Y.; Lan, L.F.; Wang, L.; Ning, H.L.; Peng, J.B. High-performance hybrid white organic light-emitting diodes employing p-type interlayers. J. Ind. Eng. Chem. 2015, 27, 240-244. [CrossRef]

154. Liu, B.; Tao, H.; Su, Y.J.; Gao, D.Y.; Lan, L.F.; Zou, J.H.; Peng, J.B. Color-stable, reduced efficiency roll-off hybrid white organic light emitting diodes with ultra high brightness. Chin. Phys. B 2013, 22, 077303. [CrossRef]

155. Liu, B.; Wang, L.; Zou, J.H.; Tao, H.; Su, Y.J.; Gao, D.Y.; Xu, M.; Lan, L.F.; Peng, J.B. Investigation on spacers and structures: A simple but effective approach toward high-performance hybrid white organic light emitting diodes. Synth. Met. 2013, 184, 5-9. [CrossRef]

156. Liu, B.; Zou, J.H.; Su, Y.J.; Gao, D.Y.; Lan, L.F.; Tao, H.; Peng, J.B. Hybrid white organic light emitting diodes with low efficiency roll-off, stable color and extreme brightness. J. Lumin. 2014, 151, 161-164. [CrossRef]

157. Zhao, B.; Zhang, H.; Miao, Y.; Wang, Z.; Gao, L.; Wang, H.; Hao, Y.; Li, W. High Color Stability and CRI (>80) Fluorescent White Organic Light-Emitting Diode based Pure Emission of Exciplexes by Employing Merely Complementary colors. J. Mater. Chem. C 2018, 6, 304-311. [CrossRef]

158. Wang, D.; Li, W.L.; Su, Z.S.; Li, T.L.; Chu, B.; Bi, D.F.; Chen, L.L.; Su, W.M.; He, H. Broad Wavelength Modulating and Design of Organic White Diode Based on Lighting by Using Exciplex Emission from Mixed Acceptors. Appl. Phys. Lett. 2006, 89, 53. [CrossRef]

159. Zhu, J.; Li, W.; Han, L.; Chu, B.; Zhang, G.; Yang, D.; Chen, Y.; Su, Z.; Wang, J.; Wu, S.; et al. Very Broad White-Emission Spectrum Based Organic Light-Emitting Diodes by Four Exciplex Emission Bands. Opt. Lett. 2009, 34, 2946-2948. [CrossRef] [PubMed]

160. Wang, Q.; Ding, J.Q.; Zhang, Z.Q.; Ma, D.G.; Cheng, Y.X.; Wang, L.X.; Wang, F.S. A high-performance tandem white organic light-emitting diode combining highly effective white-units and their interconnection layer. J. Appl. Phys. 2009, 105, 076101. [CrossRef]

161. Lei, D.; Tang, X.; Xu, M.F.; Shi, X.B.; Wang, Z.K.; Liao, L.S. Lithium Hydride Doped Intermediate Connector for High-Efficiency and Long-Term Stable Tandem Organic Light-Emitting Diodes. ACS Appl. Mater. Interfaces 2014, 6, 18228-18232.

162. Liu, B.; Wang, L.; Tao, H.; Xu, M.; Zou, J.; Ning, H.; Peng, J.; Cao, Y. Doping-Free Tandem White Organic Light-Emitting Diodes. Sci. Bull. 2017, 62, 1193-1200. [CrossRef]

163. Hong, T.; Gao, D.; Liu, B.; Wang, L.; Zou, J.; Xu, M.; Peng, J. Enhancement of tandem organic light-emitting diode performance by inserting an ultra-thin Ag layer in charge generation layer. Acta Phys. Sin. 2017, 1, 017302. [CrossRef]

164. Zhao, B.; Zhang, T.; Chu, B.; Li, W.; Su, Z.; Luo, Y.; Li, R.; Yan, X.; Jin, F.; Gao, Y.; et al. Highly efficient tandem full exciplex orange and warm white OLEDs based on thermally activated delayed fluorescence mechanism. Org. Electron. 2015, 17, 15-21. [CrossRef]

165. Hung, W.Y.; Fang, G.C.; Lin, S.W.; Cheng, S.H.; Wong, K.T.; Kuo, T.Y.; Chou, P.T. The First Tandem, All-exciplex-based WOLED. Sci. Rep. 2014, 4, 5161. [CrossRef] [PubMed]

166. Liu, B.; Li, X.; Tao, H.; Zou, J.; Xu, M.; Wang, L.; Peng, J.; Cao, Y. Manipulation of Exciton Distribution for High-Performance Fluorescent/Phosphorescent Hybrid White Organic Light-Emitting Diodes. J. Mater. Chem. C 2017, 5, 7668-7683. [CrossRef]

167. Fröbel, M.; Schwab, T.; Kliem, M.; Hofmann, S.; Leo, K.; Gather, M.C. Get It White: Color-Tunable Ac/Dc OLEDs. Light Sci. Appl. 2015, 4, e247. [CrossRef]

168. Krotkus, S.; Kasemann, D.; Lenk, S.; Leo, K.; Reineke, S. Adjustable White-Light Emission From a Photo-Structured Micro-OLED Array. Light Sci. Appl. 2016, 5, e16121. [CrossRef] 
169. Schwartz, G.; Ke, T.-H.; Wu, C.-C.; Walzer, K.; Leo, K. Balanced ambipolar charge carrier mobility in mixed layers for application in hybrid white organic light-emitting diodes. Appl. Phys. Lett. 2008, 93, 073304. [CrossRef]

170. Zhang, T.; Zhao, B.; Chu, B.; Li, W.; Su, Z.; Yan, X.; Liu, C.; Wu, H.; Gao, Y.; Jin, F.; et al. Simple structured hybrid WOLEDs based on incomplete energy transfer mechanism: From blue exciplex to orange dopant. Sci. Rep. 2015, 5, 10234. [CrossRef] [PubMed]

171. Liu, X.-K.; Chen, Z.; Qing, J.; Zhang, W.J.; Wu, B.; Tam, H.L.; Zhu, F.; Zhang, X.-H.; Lee, C.-S. Organic light-emitting devices: Remanagement of singlet and triplet excitons in single-emissive-layer hybrid white organic light-emitting devices using thermally activated delayed fluorescent blue exciplex. Adv. Mater. 2015, 27, 7079-7085. [CrossRef] [PubMed]

172. Wu, Z.; Yu, L.; Zhao, F.; Qiao, X.; Chen, J.; Ni, F.; Yang, C.; Ahamad, T.; Alshehri, S.M.; Ma, D. Precise Exciton Allocation for Highly Effcient White Organic Light-Emitting Diodes with Low Effciency Roll-Off Based on Blue Thermally Activated Delayed Fluorescent Exciplex Emission. Adv. Opt. Mater. 2017, 5, 1700415. [CrossRef]

173. Luo, D.; Li, X.-L.; Zhao, Y.; Gao, Y.; Liu, B. High-Performance Blue Molecular Emitter-Free and Doping-Free Hybrid White Organic Light-Emitting Diodes: An Alternative Concept to Manipulate Charges and Excitons Based on Exciplex and Electroplex Emission. ACS Photonics 2017, 4, 1566-1575. [CrossRef]

174. Grybauskaite-Kaminskiene, G.; Ivaniuk, K.; Bagdziunas, G.; Turyk, P.; Stakhira, P.; Baryshnikov, G.; Volyniuk, D.; Cherpak, V.; Minaev, B.; Hotra, Z.; et al. Contribution of TADF and exciplex emission for efficient "warm-white" OLEDs. J. Mater. Chem. C 2018, 6, 1543-1550. [CrossRef]

175. Luo, D.; Chen, Q.; Gao, Y.; Zhang, M.; Liu, B. Extremely Simplified, High-Performance and Doping-Free White Organic Light-Emitting Diodes Based on Single Thermally Activated Delayed Fluorescent Emitter. ACS Energy Lett. 2018, 3, 1531-1538. [CrossRef]

176. Wu, Z.; Qi, W.; Ling, Y.; Chen, J.; Qiao, X.; Ahamad, T.; Alshehri, S.M.; Yang, C.; Ma, D. Managing excitons and charges for high-performance fluorescent white organic light-emitting diodes. ACS Appl. Mater. Interfaces 2016, 8, 28780-28788. [CrossRef] [PubMed]

177. David, G.; Vygintas, J.; Dias, F.B.; Monkman, A. Photophysical Investigation of the Thermally Activated Delayed Emission from Films of m-MTDATA:PBD Exciplex. Adv. Funct. Mater. 2014, 24, 2343-2351.

178. Aizawa, N.; Pu, Y.J.; Watanabe, M.; Chiba, T.; Ideta, K.; Toyota, N.; Igarashi, M.; Suzuri, Y.; Sasabe, H.; Kido, J. Solution-Processed Multilayer Small-Molecule Light-Emitting Devices with High-Efficiency White-Light Emission. Nat. Commun. 2014, 5, 5756. [CrossRef] [PubMed]

179. Hou, L.; Duan, L.; Qiao, J.; Zhang, D.; Dong, G.; Wang, L.; Qiu, Y. Efficient Solution-Processed Small-Molecule Single Emitting Layer Electrophosphorescent White Light-Emitting Diodes. Org. Electron. 2010, 11, 1344-1350. [CrossRef]

180. Wang, Q.; Oswald, I.W.H.; Perez, M.R.; Jia, H.P.; Shahub, A.A.; Qiao, Q.Q.; Gnade, B.E.; Omary, M.A. Doping-Free Organic Light-Emitting Diodes with Very High Power Efficiency, Simple Device Structure, and Superior Spectral Performance. Adv. Funct. Mater. 2014, 24, 4746-4752. [CrossRef]

181. Wang, J.; Chen, J.; Qiao, X.; Alshehri, S.M.; Ahamad, T.; Ma, F. Simple-Structured Phosphorescent Warm White Organic Light-Emitting Diodes with High Power Efficiency and Low Efficiency Roll-off. ACS Appl. Mater. Interfaces 2016, 8, 10093-10097. [CrossRef] [PubMed]

182. Zhang, M.; Wang, K.; Zheng, C.-J.; Liu, W.; Lin, H.; Tao, S.-L.; Zhang, X.-H. Efficient, color-stable and high color-rendering-index white organic light-emitting diodes employing full thermally activated delayed fluorescence system. Org. Electron. 2017, 50, 466-472. [CrossRef]

183. Yoshihiro, O. Color rendering and luminous efficacy of white LED spectra. Proc. SPIE 2004, 88, 5530. [CrossRef]

184. Chen, Y.-H.; Ma, D.-G.; Sun, H.-D.; Chen, J.-S.; Guo, Q.-X.; Wang, Q.; Zhao, Y.-B. Organic Semiconductor Heterojunctions: Electrode-Independent Charge Injectors for High-Performance Organic Light-Emitting Diodes. Light Sci. Appl. 2016, 5, e16042. [CrossRef]

185. Sasabe, H.; Takamatsu, J.; Motoyama, T.; Watanabe, S.; Wagenblast, G.; Langer, N.; Molt, O.; Fuchs, E.; Lennartz, C.; Kido, J. High-Efficiency Blue and White Organic Light-Emitting Devices Incorporating a Blue Iridium Carbene Complex. Adv. Mater. 2010, 22, 5003-5007. [CrossRef] [PubMed]

186. Liu, B.; Lan, L.; Zou, J.; Peng, J. A novel organic light-emitting diode by utilizing double hole injection layer. Acta Phys. Sin. 2013, 62, 087302. [CrossRef] 
187. Yong, J.C.; Yook, K.S.; Lee, J.Y. Cool and Warm Hybrid White Organic Light-Emitting Diode with Blue Delayed Fluorescent Emitter Both as Blue Emitter and Triplet Host. Sci. Rep. 2015, 5, 7859. [CrossRef]

188. Kim, B.S.; Yook, K.S.; Lee, J.Y. Above 20\% External Quantum Efficiency in Novel Hybrid White Organic Light-Emitting Diodes Having Green Thermally Activated Delayed Fluorescent Emitter. Sci. Rep. 2014, 4, 6019. [CrossRef] [PubMed]

189. Preinfalk, J.B.; Eiselt, T.; Wehlus, T.; Rohnacher, V.; Hanemann, T.; Gomard, G.; Lemmer, U. Large-Area Screen-Printed Internal Extraction Layers for Organic Light-Emitting Diodes. ACS Photonics 2017, 4, 928-933. [CrossRef]

190. Koh, T.-W.; Spechler, J.A.; Lee, K.M.; Arnold, C.B.; Rand, B.P. Enhanced Outcoupling in Organic Light-Emitting Diodes via a High-Index Contrast Scattering Layer. ACS Photonics 2015, 2, 1366-1372. [CrossRef]

191. Guan, N.; Dai, X.; Messanvi, A.; Zhang, H.; Yan, J.; Gautier, E.; Bougerol, C.; Julien, F.H.; Durand, C.; Eyery, J.; Tchernycheva, M. Flexible White Light Emitting Diodes Based on Nitride Nanowires and Nanophosphors. ACS Photonics 2016, 3, 597-603. [CrossRef] [PubMed]

192. Gomez, E.F.; Steckl, A.J. Improved Performance of OLEDs on Cellulose/Epoxy Substrate Using Adenine as a Hole Injection Layer. ACS Photonics 2015, 2, 439-445. [CrossRef]

193. Gong, S.; Chen, Y.; Luo, J.; Yang, C.; Zhong, C.; Qin, J.; Ma, D. Bipolar Tetraarylsilanes as Universal Hosts for Blue, Green, Orange, and White Electrophosphorescence with High Efficiency and Low Efficiency Roll-Off. Adv. Funct. Mater. 2011, 21, 1168-1178. [CrossRef]

194. D'Andrade, B.W.; Holmes, R.J.; Forrest, S.R. Efficient Organic Electrophosphorescent White-Light-Emitting Device with a Triple Doped Emissive Layer. Adv. Mater. 2004, 16, 624-628. [CrossRef]

195. Guo, J.J.; Li, X.L.; Nie, H.; Luo, W.W.; Gan, S.F.; Hu, S.M.; Hu, R.R.; Qin, A.J.; Zhao, Z.J.; Su, S.J.; et al. Achieving High-Performance Nondoped OLEDs with Extremely Small Efficiency Roll-Off by Combining Aggregation-Induced Emission and Thermally Activated Delayed Fluorescence. Adv. Funct. Mater. 2017, 27, 1606458. [CrossRef]

196. Chen, S.; Zhao, X.; Wu, Q.; Shi, H.; Mei, Y.; Zhang, R.; Wang, L.; Huang, W. Efficient, Color-Stable Flexible White Top-Emitting Organic Light-Emitting Diodes. Org. Electron. 2013, 14, 3037-3045. [CrossRef]

197. Yook, K.S.; Jeon, S.O.; Joo, C.W.; Lee, J.Y. Color stability and suppressed efficiency roll-off in white organic light-emitting diodes through management of interlayer and host properties. J. Ind. Eng. Chem. 2009, 15, 420-422. [CrossRef]

198. Zhao, F.C.; Zhang, Z.Q.; Liu, Y.P.; Dai, Y.F.; Chen, J.S.; Ma, D.G. A hybrid white organic light-emitting diode with stable color and reduced efficiency roll-off by using a bipolar charge carrier switch. Org. Electron. 2012, 13, 1049-1055. [CrossRef]

199. Schwartz, G.; Reineke, S.; Walzer, K.; Leo, K. Reduced efficiency roll-off in high-efficiency hybrid white organic light-emitting diodes. Appl. Phys. Lett. 2008, 92, 053311. [CrossRef]

200. Wu, Z.B.; Luo, J.J.; Sun, N.; Zhu, L.P.; Sun, H.D.; Yu, L.; Yang, D.Z.; Qiao, X.F.; Chen, J.S.; Yang, C.L.; et al. HighPerformance Hybrid White Organic Light-Emitting Diodes with Superior Efficiency/Color Rendering Index/Color Stability and Low Efficiency Roll-Off Based on a Blue Thermally Activated Delayed Fluorescent Emitter. Adv. Funct. Mater. 2016, 26, 3306-3313. [CrossRef]

201. Gonzalez-Urbina, L.; Baert, K.; Kolaric, B.; Perez-Moreno, J.; Clays, K. Linear and nonlinear optical properties of colloidal photonic crystals. Chem. Rev. 2012, 112, 2268-2285. [CrossRef] [PubMed]

202. John, S.; Wang, J. Quantum electrodynamics near a photonic band gap: Photon bound states and dressed atoms. Phys. Rev. Lett. 1990, 64, 2418-2421. [CrossRef] [PubMed]

203. Kolaric, B.; Baert, K.; Van der Auweraer, M.; Vallee, R.A.L.; Clays, K. Controlling the fluorescence resonant energy transfer by photonic crystal band gap engineering. Chem. Mater. 2007, 19, 5547-5552. [CrossRef]

204. Gonzalez-Urbina, L.; Perez-Moreno, J.; Clays, K.; Kolaric, B. Phosphorescence emission from BAlq by forced intersystem crossing in a colloidal photonic crystal. Mol. Phys. 2016, 114, 2248-2252. [CrossRef]

205. Kim, M.; Jeon, S.K.; Hwang, S.H.; Lee, J.Y. Stable Blue Thermally Activated Delayed Fluorescent Organic Light-Emitting Diodes with Three Times Longer Lifetime than Phosphorescent Organic Light-Emitting Diodes. Adv. Mater. 2015, 27, 2515-2520. [CrossRef] [PubMed]

206. Shi, Z.; Li, Y.; Zhang, Y.; Chen, Y.; Li, X.; Wu, D.; Xu, T.; Shan, C.; Du, G. High-efficiency and air-stable perovskite quantum dots light-emitting diodes with an all-inorganic heterostructure. Nano Lett. 2016, 17, 313-321. [CrossRef] [PubMed] 
207. Shi, Z.; Li, Y.; Li, S.; Li, X.; Wu, D.; Xu, T.; Tian, Y.; Chen, Y.; Zhang, Y.; Zhang, B.; et al. Localized Surface Plasmon Enhanced All-Inorganic Perovskite Quantum Dot Light-Emitting Diodes Based on Coaxial Core/Shell Heterojunction Architecture. Adv. Funct. Mater. 2018, 28, 1707031. [CrossRef]

208. Shi, Z.; Li, S.; Li, Y.; Ji, H.; Li, X.; Wu, D.; Xu, T.; Chen, Y.; Tian, Y.; Zhang, Y.; et al. Strategy of solution-processed all-inorganic heterostructure for humidity/temperature-stable perovskite quantum dot light-emitting diodes. ACS Nano 2018, 12, 1462-1472. [CrossRef] [PubMed]

209. Liu, B.; Wang, L.; Xu, M.; Tao, H.; Zou, J.H.; Gao, D.Y.; Lan, L.F.; Ning, H.L.; Peng, J.B.; Cao, Y. Efficient Hybrid White Organic Light-emitting Diodes with Extremely Long Lifetime: The Effect of n-type Interlayer. Sci. Rep. 2014, 4, 7198. [CrossRef] [PubMed]

210. Wang, Z.; Liu, Z.; Zhang, H.; Zhao, B.; Chen, L.; Xue, L.; Wang, H.; Li, W. Highly efficient and spectra stable warm white organic light-emitting diodes by the application of exciplex as the excitons adjustment layer. Org. Electron. 2018, 62, 157-162. [CrossRef]

211. Chen, B.; Liu, B.; Zeng, J.; Nie, H.; Xiong, Y.; Zou, J.; Ning, H.; Wang, Z.; Zhao, Z.; Tang, B.Z. Efficient Bipolar Blue AIEgens for High-Performance Nondoped Blue OLEDs and Hybrid White OLEDs. Adv. Funct. Mater. 2018. [CrossRef]

212. Xi, Z.; Zhao, B.; Chen, L.; Li, W.; Wang, H.; Liu, X.; Xu, B. Demonstration of highly efficient orange EL device and warm white OLED. Org. Electron. 2018, 57, 21-27. [CrossRef]

213. Gao, Y.; Li, M.; Delikanli, S.; Zheng, H.; Liu, B.; Dang, C.; Sum, T.C.; Demir, H.V. Low-threshold lasing from colloidal CdSe/CdSeTe core/alloyed-crown type-II heteronanoplatelets. Nanoscale 2018, 10, 9466-9475. [CrossRef] [PubMed]

214. Xiao, P.; Huang, J.; Dong, T.; Xie, J.; Yuan, J.; Luo, D.; Liu, B. Room-temperature Fabricated Thin-Film Transistors Based on Compounds with Lanthanum and Main Family Element Boron. Molecules 2018, 23, 1373. [CrossRef] [PubMed]

215. Xiao, P.; Huang, J.; Yan, D.; Luo, D.; Yuan, J.; Liu, B.; Liang, D. Emergence of Nanoplatelet Light-Emitting Diodes. Materials 2018, 11, 1376. [CrossRef] [PubMed] 